\title{
Pricing, Production and Persistence
}

\author{
Michael Dotsey* and Robert G. King**
}

July 2001

\begin{abstract}
Though built with increasingly precise microfoundations, modern optimizing sticky price models have displayed a chronic inability to generate large and persistent real responses to monetary shocks, as recently stressed by Chari, Kehoe and McGrattan [2000]. This is an ironic finding, since Taylor [1980] and other researchers were motivated to study sticky price models in part by the objective of generating large and persistent business fluctuations.

We trace this lack of persistence to a standard view of the cyclical behavior of real marginal cost built into current sticky price macro models. Using both a small loglinear macroeconomic model and a larger fully articulated model, we show how an alternative view of real marginal cost can lead to substantial persistence. This alternative view is based on three features of the "supply side" of the economy that we believe are realistic: an important role for produced inputs, variable capacity utilization, and labor supply variability through changes in employment. Importantly, these "real flexibilities" work together to dramatically reduce the elasticity of marginal cost with respect to output, from levels much larger than unity in CKM to values much smaller than unity in our analysis. These "real flexibilities" consequently reduce the extent of price adjustments by firms in time-dependent pricing economies and the incentives for paying fixed costs of adjustment in state-dependent pricing economies. The structural features also lead the sticky price model to display volatility and comovement of factor inputs and factor prices that are more closely in line with conventional wisdom about business cycles.
\end{abstract}

${ }^{*}$ Federal Reserve Bank of Richmond; ** Boston University, NBER and FRB Richmond. Brian Boike provided excellent research assistance. Any errors remain our sole responsibility. This paper builds on earlier joint work with Alexander L. Wolman on this topic. 


\section{Introduction}

Many macroeconomists believe that price stickiness is necessary for generating persistent real economic responses to shifts in monetary policy. Many recent macroeconomic models have incorporated this feature through staggering in the style of Taylor [1980] to study the consequences of monetary shocks and alternative monetary policy rules. Increasingly these macroeconomic models are being built under the discipline imposed by solid microeconomic foundations, with the hope that they will better match actual economic behavior and be more suitable for use in normative analysis ${ }^{1}$.

However, as these macroeconomic models have developed better microfoundations, a chronic finding has been that there is little persistence in the response of real economic activity to nominal shocks. Recently, this "persistence problem" has been highlighted by Chari, Kehoe, and McGrattan [2000]. These authors display the persistence problem in a standard calibration of a general equilibrium model with sticky prices and imperfect competition; they also show that the problem continues to arise under many different parameter settings and with many different model modifications that have been suggested in the literature. While they do not disagree that monetary policy shocks may have persistent effects empirically, CKM [2000] instead claim that microfoundations provide restrictions that eliminate the persistence of fluctuations found in early nominal rigidity models developed by Taylor and others. In particular, they indicate that "in versions of our model without intertemporal links, staggered price-setting leads to persistent output fluctuations after monetary shocks, but once such links are introduced, output fluctuations are no longer persistent." In essence, the message is that the effect of imposing quantitative general equilibrium discipline on New Keynesian economics is to destroy its empirical promise.

By contrast, we suggest that constructing a more realistic general equilibrium macroeconomic model will lead to substantial persistence and otherwise enhance the empirical promise of this class of models. Our counter-argument is based on three key aspects of the production structure that are central to real business cycle analysis. These features are relevant across many industries in most modern economies and involve: (1) a substantial role for produced inputs, (2) significant variability in capacity utilization, and (3) variation in labor supply along an extensive margin. Each of these supply-side features allows for a more elastic response of output to demand without increased marginal cost, so we term these "real flexibilities" ${ }^{2}$.

\footnotetext{
${ }^{1}$ Goodfriend and King [1997] describe such models, which blend the New Keynesian mechanisms of imperfect competition and sticky prices with the classical real business cycle model, as the New Neoclassical Synthesis.

${ }^{2}$ By contrast Ball and Romer [1993] study various market imperfections that impede the response of
} 
Working in a simple loglinear business cycle framework related to that of Taylor [1980], we show that these supply-side elements substantially reduce the sensitivity of marginal cost to variations in aggregate output. That is: smaller variations in marginal cost lead firms to make smaller price adjustments or to adjust less frequently or both, which diminishes the sensitivity of the price level to changes in aggregate demand. In turn, the increased sluggishness of the price level leads to increased persistence of output. In addition, when we include these features in a fully articulated quantitative general equilibrium model they continue to lead to substantial sluggishness in the price level and substantial persistence in output fluctuations.

In addition to producing persistent real effects of monetary shocks, our model economies also have other implications that make them more consistent with conventional wisdom about cyclical fluctuations. First, economists have long noted that, over the course of business cycles, the level of real economic activity varies sharply with apparently small accompanying changes in the real rewards to capital and labor. Second, dating back to at least Burns and Mitchell [1946], students of business cycles have noted that the movements in output and labor input are approximately proportionate at both the industry and aggregate level. Third, in many industries materials input is a large fraction of gross output, which varies cyclically in a manner that is also roughly proportionate to gross output and value-added. Fourth, when measures of varying capacity utilization are constructed, these measures display substantial cyclical variability, at least as great as that of labor. Fifth, in most industries, the bulk of business cycle variations in total man-hours are accounted for by changes in employment rather than in hours-per-worker.

Without real flexibilities, our model would have great difficulty accounting for the above mentioned stylized facts. For example, without variable capacity utilization and holding productivity fixed, the standard aggregate model implies that output will change roughly two-thirds as much as labor input. Without real flexibilities, our model would also suggest implausibly large variations in factor prices, notably in wages, relative to the output response. In studying the effects of real flexibilities our work is related Kimball [1995], who studies mechanisms for reducing the responsiveness of marginal cost to output, and Bergin and Feenstra [2000], who explore the role of intermediate inputs. Like these earlier authors, we find that increased supply elasticities and materials inputs separately contribute to increased persistence, but we also find that their effects on persistence are mutually reinforcing.

Although our models generate substantial persistence, they also generate some puzzling predictions. Substantial expected inflation arises because the monetary shocks studied are ones that raise the long-run path of the price-level and because the price level only adjusts factor prices and marginal cost to changes in output, which they label "real rigidities." 
gradually. As a result, nominal interest rates rise in response to positive monetary injections: this is another recurrent result for this class of models. Some have argued that this interest rate response, by itself, is a fatal deficiency of the class of models since monetary expansions are widely taken to lower rather than raise the nominal interest rate. However, we suspect this implication can be overturned by incorporating a more realistic specification of monetary policy without overturning the central result that monetary policy shocks lead to persistent changes in economic activity.

The organization of the paper is as follows. Section 2 discusses the implications that the production structure has for the cyclical behavior of real marginal cost. It contrasts the implication of two views: the standard perspective that the elasticity of real marginal cost with respect to output is quite high, as imbedded in CKM [2000], with the implications of our production structure, which makes it quite small. Section 3 uses a simple loglinear macroeconomic model to highlight how these alternative views of the elasticity of real marginal cost with respect to output translate into predictions about the persistence of output. Section 4 provides an overview of our fully articulated macroeconomic model, which is then used to evaluate the general equilibrium dynamics in response to monetary disturbances. Section 5 shows how the persistence of output depends on structural features of this economy. Section 6 is a conclusion.

\section{Marginal cost and the supply side}

The cyclical behavior of real marginal cost plays a central role in modern business cycle models with imperfect competition and sticky prices. In turn, the supply side of the model economy governs how the cyclical behavior of real marginal cost is related to the level of output and this relationship is critical for the cyclical comovement of factors of production and relative prices. In this section, we highlight two alternative visions of the supply-side determinants of real marginal cost and factor variability: a standard one that is present in many models in the literature and an alternative one that stresses materials inputs, variable capacity utilization, and variable labor supply on the extensive margin. In the subsequent sections of the paper we then build this supply side into a small loglinear model and a fully articulated macroeconomic model. 


\subsection{The standard view of marginal cost and output}

The standard view of the link between marginal cost and output does not involve intermediate inputs or variable capacity utilization ${ }^{3}$. With a constant returns to scale production function and economy-wide competitive factor markets,

$$
\log \left(y_{t} / y\right)=\alpha \log \left(n_{t} / n\right)+(1-\alpha) \log \left(k_{t} / k\right)
$$

where $\alpha$ is labor's cost share in output, $y_{t}$ is output, $n_{t}$ is labor input and $k_{t}$ is the stock of capital as well as the relevant measure of capital input (a variable without a time subscript indicates a steady state value). Further, with any constant returns to scale technology real marginal cost is related to input prices according to

$$
\log \left(\psi_{t} / \psi\right)=\alpha \log \left(w_{t} / w\right)+(1-\alpha) \log \left(q_{t} / q\right)
$$

where $w_{t}$ is the real wage rate and $q_{t}$ is the rental price of capital.

The preceding two equations have important implications for some of the stylized facts about fluctuations that were mentioned in the introduction. First, since capital input is largely fixed, models developed along these lines have difficulty matching the observed cyclical behavior of output and labor input, which is roughly proportionate. In the model, labor must be more volatile. For example, with $\alpha=2 / 3$, a 1 percent increase in output requires a 1.5 percent increase in labor input. Second, real marginal cost is fundamentally governed by movements in factor prices: if these are sensitive to cyclical variations in output, marginal cost will also be highly sensitive.

To study the implications for factor prices it is convenient to use a Cobb-Douglas production function implying that $\log \left(q_{t} / q\right)-\log \left(w_{t} / w\right)=\log \left(n_{t} / n\right)-\log \left(k_{t} / k\right)$. With aggregate capital fixed in any given period and for convenience normalized to its steady state value, its rental price is thus related to output according to $\log \left(q_{t} / q\right)=\log \left(w_{t} / w\right)+\frac{1}{\alpha} \log \left(y_{t}\right)$. Assuming that there is a labor supply schedule of the form

$$
\log \left(n_{t} / n\right)=\zeta_{w} \log \left(w_{t} / w\right)-\zeta_{y} \log \left(y_{t} / y\right)
$$

labor market equilibrium will require that $\log \left(w_{t} / w\right)=\frac{1+\alpha \zeta_{y}}{\alpha \zeta_{w}} \log \left(y_{t} / y\right)^{4}$, so that the behavior of real marginal cost is

$$
\log \left(\psi_{t} / \psi\right)=\left\{\left[\frac{(1-\alpha)}{\alpha}\right]+\left[\frac{1 / \alpha+\zeta_{y}}{\zeta_{w}}\right]\right\} \log \left(y_{t} / y\right)=\phi \log \left(y_{t} / y\right)
$$

\footnotetext{
${ }^{3}$ The standard analysis of the cyclical behavior of real marginal cost is based on a Cobb Douglas production function and is described by Bils [1987]. It has been built into general equilibrium sticky price models of the Calvo sort by King and Wolman [1996] and Yun [1996] and forms the reference case for Chari et al [2000].

${ }^{4}$ While we work with a labor supply schedule here, we note that Dotsey et al. [1999] assume that there is no aggregate variation in capital and that there is a representative consumer with a utility function $\frac{1}{1-\sigma} c^{1-\sigma}-\frac{\chi}{1+\gamma}(1-l)^{1+\gamma}$. This preference specification gives rise to the labor supply schedule in the text,
} 
This expression highlights two aspects of the cyclical behavior of marginal cost. More specifically, it shows two influences on the elasticity of real marginal cost with respect to output, which we call $\phi$ here and below. The first bracketed term reflects the increase in the rental rate on capital. Additional labor is required to produce additional output and this additional labor increases the marginal product of capital, thus raising its rental price proportionately in the Cobb-Douglas case. Given that the cost share of capital is $(1-\alpha)$, the overall effect is $\left[\frac{(1-\alpha)}{\alpha}\right]=\frac{1}{2}$ if labor's share is $\alpha=2 / 3$. The second bracketed term involves the change in wages, which in turn depend on the labor supply elasticity $\zeta_{w}$ and the effect of output on labor supply $\zeta_{y}$, as well as the slope of the effective demand for labor. ${ }^{5}$ For example, if $\zeta_{y}=\zeta_{w}=1$ then the second bracketed expression is $5 / 2$ implying a value of $\phi=3$ under the traditional view. Thus, marginal cost responds highly elastically to output. Also, as the labor supply elasticity becomes infinite $\phi$ takes on its minimum value of $\left[\frac{(1-\alpha)}{\alpha}\right] .{ }^{6}$

\subsection{An alternative view based on real flexibilities}

A quite different view of the links between marginal cost, inputs, and output is suggested by the models that we construct in this paper, which feature: (i) materials inputs, (ii) elastic factor supply, and (iii) small reasons for firms to substitute between inputs, either due to technology or relative factor price movements. Specifically, we make two sets of assumption about factor supply that differ from the standard view. First, we assume that capital services are influenced by both the capital stock and the utilization rate $\left(z_{t}\right)$, with the quantity of capital services given by $k_{t}^{s}=z_{t} k_{t}$. As explained in more detail later in the paper, we assume that a higher rate of utilization involves higher marginal depreciation costs, implying that utilization is an increasing function of the rental rate. To a first approximation, this supply of capital services can be written as

$$
\log \left(q_{t} / q\right)=\xi \log \left(z_{t} / z\right)
$$

under some assumptions that are worth highlighting. Initially, assume that consumption and output move together with $\log \left(c_{t} / c\right)=\tau \log \left(y_{t} / y\right)$. Then, it follows that the labor supply schedule would take the form in the text with $\zeta_{w}=1 / \gamma$ and $\zeta_{y}=\sigma * \tau$. In many of the numerical examples in the text we will assume $\sigma=\tau=1$, as suggested by a model in which there is balanced growth and consumption and investment are identical. Further, with $\tau \neq 1$, the model can be used to mimic economies with consumption volatility calibrated to be some fraction of output volatility.

${ }^{5}$ As in the general disequilibrium literature of the late 1970s, the labor demand that is relevant in the current discussion is given by the requirement that a given level of output be produced. The prior discussion indicates that labor demand may therefore be written $\operatorname{as} \log \left(n_{t} / n\right)=(1 / \alpha) \log \left(y_{t} / y\right)$. Thus the slope is $1 / \alpha$, which is the first term in the numerator of the second bracketed expression.

${ }^{6}$ Continuing the discussion of footnote 4, Dotsey et. al. [1999] study a reference case in which $\zeta_{y}=1$ and values of $\zeta_{w}$ between $\infty$ and .2. They find small output and not very persistent output effects. 
where $\xi$ is an inverse supply elasticity. Second, we assume there is variation in both hours per worker $\left(h_{t}\right)$ and the number of employed individuals $\left(e_{t}\right)$, with the total quantity of manhours being given by $n_{t}=h_{t} e_{t}$. Consistent with much empirical work on business cycles, we assume that the employment rate responds substantially over the cycle, making the supply of elasticity for total hours much larger than the supply elasticity of hours per worker. This accords with the analysis of the effect of wages on labor supply in Mulligan [1998].

Intermediate inputs with limited factor substitution: A typical firm in our economy has a production function for gross output of the nested constant returns-to-scale form $((2.2)$ and $(2.3)$ ), where gross output $y_{t}^{g}$ is a function of a materials input aggregate (to be discussed further below) in the amount $x_{t}$ and another aggregate $y_{t}$, which we will interpret as the firm's value-added. The value-added input is a function of labor input (in man-hours $n_{t}$ ) and capital services input (in amount $k_{t}^{s}$ ).

$$
\begin{aligned}
y_{t}^{g} & =g\left(x_{t}, y_{t}\right) \\
y_{t} & =f\left(n_{t}, k_{t}^{s}\right)
\end{aligned}
$$

For illustrative purposes in this section, we will assume that both $g$ and $f$ are essentially fixed proportions implying that intermediate inputs, gross output and net output move onefor-one together, and that net output, labor and capital utilization also move together in a one-for-one manner.

But, even though our production functions are assumed to have low elasticities of substitution, it is still the case that there are first-order approximations to the levels of gross and net output resembling those of the basic model.

$$
\begin{aligned}
\log \left(y_{t}^{g} / y^{g}\right) & =s_{x} \log \left(x_{t} / x\right)+\left(1-s_{x}\right) \log \left(y_{t} / y\right) \\
\log \left(y_{t} / y\right) & =\alpha \log \left(n_{t} / n\right)+(1-\alpha)\left[\log \left(z_{t} / z\right)+\log \left(k_{t} / k\right)\right]
\end{aligned}
$$

where $s_{x}$ is the share of intermediate inputs in gross output and $\alpha$ is labor's share in net output (value added). One key implication is that even with the capital stock held fixed, demand-induced changes in net output can now be accommodated through changes in factors of production other than labor.

Further, the loglinear equation governing the relationship between marginal cost and factor prices is

$$
\begin{aligned}
\log \left(\psi_{t} / \psi\right) & =s_{x} \log \left(p_{x t} / p_{x}\right)+s_{n} \log \left(w_{t} / w\right)+s_{k} \log \left(q_{t} / q\right) \\
& =s_{n} \log \left(w_{t} / w\right)+s_{k} \log \left(q_{t} / q\right)
\end{aligned}
$$

with the factor shares given by $s_{n}=\left(1-s_{x}\right) \alpha$; and $s_{k}=\left(1-s_{x}\right)(1-\alpha)$. The second equality follows from our assumption that materials input is a perfect substitute for both consumption and investment. Thus, materials input has a relative price of one. 
The last expression highlights the quantitative importance of introducing materials input for the relationship between real marginal cost and the prices of labor and capital input. For example, assuming that materials inputs have a cost share $s=2 / 3$ of gross output, which is a representative value from the Annual Survey of Manufactures, and that labors share in net output is also $2 / 3$, then it follows that $s_{n}=(2 / 3) *(2 / 3)=2 / 9=.22$ and $s_{k}=(2 / 3) *(1 / 3)=1 / 9=.11$. Thus, the introduction of materials input substantially reduces the responsiveness of real marginal cost to changes in $w$ and $q$.

Marginal cost and factor supply: In the fixed proportion case, net output, labor and utilization all move proportionately $\left(\log \left(y_{t} / y\right)=\log \left(n_{t} / n\right)=\log \left(z_{t} / z\right)\right)$. Hence, factor prices must be determined on the factor supply side. Using (2.1), the response of the rental rate to output is

$$
\log \left(q_{t} / q\right)=\xi \log \left(y_{t} / y\right) .
$$

In contrast to the standard view, the rental rate now depends on the supply elasticity for capital services.

Again assuming that the labor supply function is $\log \left(n_{t} / n\right)=\zeta_{w} \log \left(w_{t} / w\right)-\zeta_{y} \log \left(y_{t} / y\right)$, it follows that the wage rate's response to output is

$$
\log \left(w_{t} / w\right)=\frac{1+\zeta_{y}}{\zeta_{w}} \log \left(y_{t} / y\right)
$$

Notice that the real wage is less sensitive to output than in the previous solution, in which the comparable coefficient is $\frac{1 / \alpha+\zeta_{y}}{\zeta_{w}}$. There is a smaller effect in the numerator because labor demand does not need to bear the entire burden of producing increased output: utilization is varied one-for-one with labor.

Combining these expressions with the loglinear equation governing the relationship between marginal cost and factor prices, we find that

$$
\begin{aligned}
\log \left(\psi_{t} / \psi\right) & =\left(1-s_{x}\right)(1-\alpha) \log \left(q_{t} / q\right)+\left(1-s_{x}\right) \alpha \log \left(w_{t} / w\right) \\
& =\left(1-s_{x}\right)\left[(1-\alpha) \xi+\alpha \frac{1+\zeta_{y}}{\zeta_{w}}\right] \log \left(y_{t} / y\right)=\phi \log \left(y_{t} / y\right)
\end{aligned}
$$

A number of key results follow from this expression concerning the determinants of the elasticity of real marginal cost with respect to output, which we again call $\phi$. First, the use of intermediate inputs (incorporated by the term $s_{x}$ ), as well as elastic factor supply (small $\xi$ and large $\zeta_{w}$ ) reduce the sensitivity of marginal cost to output. In concert, these features can have are particularly powerful effect. Second, it is a general equilibrium labor supply elasticity that is relevant for the elasticity of marginal cost $\phi$, i.e., one which takes into account shifts $\left(\zeta_{y}\right)$ as well as its slope $\left(\zeta_{w}\right)$. These features will also carry over to the model that we develop in section 4 below. 
A benchmark calculation under the alternative view: We can also use this expression to undertake a benchmark calculation similar to that done for the standard view above, where we learned that a lower bound was $\phi=3$. As an example, suppose that the share of materials in gross costs is two-thirds $\left(s_{x}=2 / 3\right)$ and that the share of labor in value added is two-thirds $(\alpha=2 / 3)$. Mulligan [1998] suggests that labor supply elasticities with both intensive and extensive margins can easily be as large as 2 and Basu and Kimball [1997]'s empirical work suggests a utilization elasticity of $\xi=1$, although larger values are also not unreasonable. Then, if there are no general equilibrium effects on labor supply, the computed lower bound for $\phi=(1 / 3) *[(1 / 3) * 1+(2 / 3) *(1 / 2)]=(2 / 9)=.1667$. The elasticity of marginal cost is higher if there are general equilibrium effects on labor supply. For example, using a standard value of $\zeta_{y}=1$, then $\phi=(1 / 3) *[(1 / 3) * 1+(2 / 3) *(2 / 2)]=1 / 3=.333 .^{7}$ Thus, the class of models developed here can easily yield an elasticity of real marginal cost with respect to output that is much less than unity.

\section{A simple instructive macro model}

We highlight the macroeconomic issues using a simple log-linear rational expectations model along the lines of Sargent [1978] and Taylor [1980]. In doing so we are able to highlight the relationship between various key elasticities, the production structure, and persistence.

\subsection{Price adjustment and marginal cost}

The model combines the supply side features just derived with the monopolistically competitive setting of Blanchard and Kiyotaki [1987] together with sticky prices modeled along the lines of Calvo [1983]. These features imply two equations governing the behavior of prices. One is a backward looking price level equation that is a weighted average of the nominal prices set in prior periods $\left(P_{t-j}^{*}\right)$. It takes a particularly simple form under Calvo's assumption that price adjustment opportunities arrive to firms with probability $(1-\eta)$ each period. The price level equation is

$$
\log P_{t}=(1-\eta) \sum_{j=0}^{\infty} \eta^{j} \log P_{t-j}^{*}=\eta \log P_{t-1}+(1-\eta) \log P_{t}^{*}
$$

which can be rewritten as a partial adjustment mechanism, $P_{t}-P_{t-1}=(1-\eta)\left[P_{t}^{*}-P_{t-1}\right]$. The partial adjustment interpretation indicates that the price level responds only gradually when

\footnotetext{
${ }^{7}$ The sense in which $\zeta_{y}=1$ is a standard value is based on the discussion of footnote 4: it is consistent with balanced growth $(\sigma=1)$ and consumption equal to output $(\tau=1)$, which is a condition frequently imposed in small macro models of the form developed in the current section.
} 
$P_{t}^{*}$ is raised above $P_{t-1}$ with the extent of price level adjustment equal to the microeconomic probability of price adjustment. The other equation is forward looking reflecting the fact that firms understand that their prices may be sticky in future periods. They appropriately set their price to maximize a discounted expected stream of profits. Thus, current price-setting depends on future nominal marginal cost,

$$
\begin{aligned}
\log P_{t}^{*} & =(1-\beta \eta) \sum_{j=0}^{\infty}(\beta \eta)^{j} E_{t}\left[\log \left(\psi_{t+j} / \psi\right)+\log P_{t}\right] \\
& =\eta \beta E_{t} \log P_{t+1}^{*}+(1-\beta \eta)\left[\log \left(\psi_{t} / \psi\right)+\log P_{t}\right]
\end{aligned}
$$

where $\psi_{t}$ is real marginal cost and $\psi$ is the steady state value of real marginal cost.

\subsection{The persistence problem}

If we combine the analysis of the preceding two sections with a simple money demand equation $\left(\log M_{t}-\log P_{t}=\gamma \log y_{t}\right)$ and a money supply rule of the form $\left(\log M_{t}-\log M_{t-1}=\right.$ $\left.\rho\left(\log M_{t-1}-\log M_{t-2}\right)+e_{t}\right)$, then it is possible to work out the dynamic solutions for output and the price level explicitly:

$$
\begin{aligned}
\log P_{t} & =\theta \log P_{t-1}+(1-\theta)(1-\beta \theta) \sum_{j=0}^{\infty}(\beta \theta)^{j} E_{t}\left(\log M_{t+j}\right) \\
& =\theta \log P_{t-1}+(1-\theta) \log M_{t-1}+\frac{1-\theta}{1-\theta \beta \rho}\left(\log M_{t}-\log M_{t-1}\right)
\end{aligned}
$$

where $\theta$ is the smaller root-which can be shown to be between zero and one of the equation $\beta z^{2}-[1+\beta+\varphi] z+1=0$ with $\varphi=\frac{(1-\eta)(1-\beta \eta) \phi}{\eta \gamma} .8$ Further, since $\gamma y_{t}=M_{t}-P_{t}$, the model's implications for output are readily calculated

$$
\log \left(y_{t} / y\right)=\left(\frac{\theta}{\gamma} \frac{1-\beta \rho}{1-\theta \beta \rho}\right)\left[\log M_{t}-\log M_{t-1}\right]+\theta\left[\log \left(y_{t-1} / y\right)\right]
$$

This solution can be used to highlight the persistence problem. The parameter $\eta$ is a structural measure of price-stickiness persistence, built into the model. If the expected duration of a price is two quarters for example, then $\eta=1 / 2$. By contrast, $\theta$ is a system measure of the model's implication for output and price persistence, which is influenced by the elasticity of real marginal cost with respect to output, $\phi$, the income elasticity of the demand for money, $\gamma$ and so forth. When $\beta$ is close to one, then it follows that $\theta \gtrless \eta$ as $\frac{\phi}{\gamma} \lessgtr 1$. That is, with a money demand elasticity of one and values of $\phi>1$ under the standard view,

\footnotetext{
${ }^{8}$ See the appendices to King [2001] for a derivation of this solution and the implication that $0<\theta<1$.
} 
one does not obtain greater system persistence $(\theta)$ than structural persistence. ${ }^{9}$ This is the CKM [2000] result.

For concreteness we work through the following example. Let the income elasticity of money demand, $\gamma$ be 1 and take the standard view of marginal cost, which implies a value of $\phi=3$. With this parameterization, there will be less system persistence $(\theta)$ than structural persistence $(\eta)$ because the elasticity $\phi$ exceeds one. This result is shown graphically in Figure 3.1 The simulation also highlights other features of the sticky price model when combined with the conventional production structure.

Exogenous shocks and assumed rigidities: In panel D, the monetary shock is shown as the dashed line: there is a one percent increase in money at the impact date $(t=1)$ and the positive serial correlation in money growth leads to a gradual increase to a level of the money stock which is two percent higher in the long run. In panel A, the extent of exogenous persistence parameterized by $\eta=.5$ is illustrated by the '*' path: it is .5 at date $\mathrm{t}=1 ; .5^{2}=.25$ at date $\mathrm{t}=2$ and so forth.

Response of the price level and output: The response of output as shown in panel A is small relative to the assumed price rigidity: there is an impact effect on output of less than $.2 \%$ even though half of the firms have sticky prices. The output effect is also not very persistent, although the Calvo form of pricing means that it dies away gradually rather than simply stopping immediately as in the finite lag overlapping contracts model used in the simulations of CKM [2000]. Given the quantity equation, this small output response is inversely related to a rapid price level response, which is shown in panel D. Even though only half the firms can adjust their prices at date 1 , the price level rises by $.8 \%$ on impact because adjusting firms face a high marginal cost and foresee future inflation, so that they adjust their prices by $1.5 \%$ in response to a one percent monetary shock.

Response of labor, relative prices and real marginal cost: Panel B shows that labor responds more elastically than output. With $\alpha=2 / 3$ the response is 1.5 times as large as output. Panel $\mathrm{C}$ shows that real marginal cost rises substantially, which is directly related to the parameterization of $\phi=3 .^{10}$

\footnotetext{
${ }^{9}$ One also sees that a lower income elasticity of money demand makes it more difficult for the model to generate persistence. This result is a general equilibrium feature of the model. For any given change in money and the corresponding change in output, a lower income elasticity requires a larger price level response to equilibrate the money market. The larger impact effect on the price level and hence on adjusting firms prices tends to speed up the price adjustment response to the shock. We will see below that a similar argument is true for the interest elasticity of money demand in that a larger interest elasticity reduces the endogenous persistence of the model.

${ }^{10}$ The separate components of real marginal cost are also illustrated: since capital is in fixed supply, while
} 


\subsection{Persistence with the alternative view of marginal cost, inputs, and output}

In our discussion of the alternative view of marginal cost in section 2, we considered the elasticity of marginal cost to output under the following assumptions about parameters: a materials input share of two-thirds $\left(s_{x}=2 / 3\right)$; labor's share of net output of two-thirds $(\alpha=2 / 3)$; a unit elastic supply of capacity $(\xi=1)$; and some additional assumptions about labor (a labor supply wage elasticity of $\zeta_{w}=2$ and a general equilibrium labor supply shift of $\zeta_{y}=1$ ). Taking all of these parameters together, we found that $\phi=.333$.

Using this elasticity of marginal cost with respect to output we now find that there are quantitatively large persistence effects. With $\beta$ essentially one, it follows that

$$
\varphi=\frac{(1-\eta)(1-\beta \eta) \phi}{\eta \gamma}=\frac{(1 / 2)(1 / 2)}{(1 / 2)} \frac{.33}{1}=.16
$$

implying that $\theta$ in equation (3.4) is .66 and that there is now more system persistence than exogenous structural persistence.

Figure 3.2 shows the simulated response of the simple macroeconomic model to a monetary shock under the alternative view of real marginal cost's relationship to output. Some aspects of this diagram can be easily calculated from the solution for output given above, $\left(\log \left(y_{t} / y\right)=\left(\frac{\theta}{\gamma} \frac{1-\beta \rho}{1-\theta \beta \rho}\right)\left[\log M_{t}-\log M_{t-1}\right]+\theta\left[\log \left(y_{t-1} / y\right)\right]\right)$. Using $\rho=.5$, this solution indicates that there is an impact output multiplier with respect to a money shock, $e_{t}$, equal to $\left(\frac{\theta}{\gamma} \frac{1-\beta \rho}{1-\theta \beta \rho}\right)=.5$ and a total multiplier ${ }^{11}$ of $\left(\frac{\theta}{\gamma} \frac{1-\beta \rho}{1-\theta \beta \rho}\right) \frac{1}{1-\rho} \frac{1}{1-\theta}=3$. By contrast in Figure 3.1, these effects are .19 and .54 respectively. As a measure of the persistence of real output, we have found it convenient to compute the mean lag. Letting $\kappa_{j}$ be the impulse response coefficient for output at lag $j$, the mean lag is the ratio of $\sum_{j=0}^{\infty} j * \kappa_{j}$ to the total multiplier $\sum_{j=0}^{\infty} \kappa_{j} .{ }^{12}$ For the basic model of Figure 3.1, this mean lag is 1.45 quarters. By contrast the model in Figure 3.2, produces a mean lag of 2.83 quarters. The near doubling of this mean lag captures the shift in the impulse response distribution from one that is concentrated in the first few quarters to one that is much more persistent.

labor is not, the rental rate rises by more than the real wage rate.

${ }^{11}$ The total multiplier can be calculated easily because

$$
\begin{aligned}
\log \left(y_{t} / y\right) & \left.=\left(\frac{\theta}{\gamma} \frac{1-\beta \rho}{1-\theta \beta \rho}\right)\left[\log M_{t}-\log M_{t-1}\right]+\theta\left[\log \left(y_{t} / y\right)\right]\right) \\
& =\left[\frac{1}{1-\theta L}\left(\frac{\theta}{\gamma} \frac{1-\beta \rho}{1-\theta \beta \rho}\right) \frac{1}{1-\rho L}\right] e_{t}
\end{aligned}
$$

To do so, we "evaluate" the bracketed expression at $L=1$ as in the main text. This is a basic application of $z$-transform methods, as discussed for example in Sargent [1978].

${ }^{12}$ In practice, we truncate the sums in these expressions at 12 quarters, but it makes little difference to the computed mean lag if we add more terms. 
The movements in real marginal cost, the wage rate, and the rental rate on capital services are shown Panel $\mathrm{C}$ of Figure 3.2. Because utilization adjusts one-for-one with the rental price, the path for the real rental rate mimics the path of output exactly. For the parameter values described above, the general equilibrium elasticity of the wage with respect

to output is $\frac{1+\zeta_{y}}{\zeta_{w}}=\frac{2}{2}=1$ so that the real wage is also exactly as variable as output. But, real marginal cost moves by only one-third as much because there is a materials share $s_{x}=2 / 3$.

The modest movements in real marginal cost means that adjusting firms are less aggressive in panel D of Figure 3.2 relative to panel D of Figure 3.1. Notably, the firms in Figure 3.2 choose to set a price $P^{*}$ that rises by roughly the same percent as the money stock on impact. Since the price level is partly predetermined, this means that it responds sluggishly. Further, later in the impulse response, both $P^{*}$ and $P$ trail increases in the money stock. This behavior contrasts to the dramatic "over adjustment" by price-setting firms in Figure 3.1 .

\subsection{Summary of results from loglinear macro model}

We interpret the results from the loglinear macroeconomic model as bearing three key messages.

(1) Under the conventional view of real marginal cost, the loglinear macroeconomic model produces little persistence in the effect of monetary shocks because marginal cost is highly sensitive to output.

(2) Under our alternative view of real marginal cost, the loglinear macroeconomic model suggests that there can be important persistence. When a monetary shock has a total output multiplier of 3 , only .5 of the output effect occurs in the first period with the bulk of the effects occurring in subsequent periods.

(3) Within our alternative view of real marginal cost, the materials input share and the general degree of factor elasticity work as mutually reinforcing mechanisms to lower the elasticity of marginal cost with respect to output and to increase the extent of persistence.

But an important subtheme of the Chari, Kehoe and McGrattan [2000] article is that results in simple loglinear macroeconomic models can easily disappear in fully articulated dynamic models that feature intertemporal mechanisms, such as capital accumulation. To explore this idea and to more consistently model the nature of linkages in intertemporal general equilibrium, we now develop a fully articulated macroeconomic model. 


\section{Structure of a fully articulated macro model}

The fully articulated macroeconomic model features the structural elements highlighted above, but is based on careful microeconomic foundations. Our discussion highlights three key ingredients of our model, treating each in a separate subsection: the nature of dynamic pricing given marginal cost; the effect of materials input on marginal cost; and the effect of factor supply on marginal cost.

\subsection{Dynamic Pricing}

In Dotsey, King and Wolman [1999], we described a model of firm pricing that (i) highlights the roles of monopolistic competition and price stickiness stressed by New Keynesian economics; (ii) is flexible enough to handle a wide range of time-dependent pricing models (including that of Calvo [1983] and the models in the style of Taylor [1980]) as well as a new state-dependent pricing model; and (iii) is operational in that it can be integrated easily into a complete general equilibrium model. In this subsection, we give a quick summary of that approach.

As is standard in the literature, we assume that each firm $j$ faces a demand curve for its product which takes the constant elasticity form (as in Blanchard-Kiyotaki [1987], and Rotemberg [1987]):

$$
d_{j t}=\left(\frac{P_{j t}}{P_{t}}\right)^{-\varepsilon} d_{t}
$$

where $P_{j t}$ is the firm's nominal price, $P_{t}$ is the price level, $\varepsilon$ is the elasticity of demand and $d_{t}$ is an aggregate demand shifter that will be discussed further below.

Some key features of pricing adjustment frictions in our economy are highlighted in Figure 4.1, which is taken from Dotsey et al [1999] with slight modification. Within each period, some firms will adjust their price and all adjusting firms will choose the identical value, which we call $P_{t}^{*}$. We now assume that there is a discrete distribution of firms, with firms of type $j$ having last set their price $j$ periods ago at the level $P_{t-j}^{*}$, so that we refer to $j$ as the vintage of the price. At the start of each period, there is a discrete distribution of firms, with fractions $\theta_{j t}(j=1,2, . ., J)$. If these firms do not adjust at date $\mathrm{t}$, they will continue to charge $P_{t-j}^{*}{ }^{13}$ In period t, a fraction $1-\eta_{j t}$ of vintage $j$ firms decides to adjust its price, and a fraction $\eta_{j t}$ decides not to adjust its price (all vintage $J$ firms choose to adjust). The total fraction of adjusting firms $\left(\omega_{0 t}\right)$ satisfies

$$
\omega_{0 t}=\sum_{j=1}^{J}\left(1-\eta_{j t}\right) \theta_{j t} .
$$

\footnotetext{
${ }^{13}$ Since all firms are in one of these situations, $\sum_{i=1}^{J} \theta_{i t}=1$.
} 
There are corresponding fractions of firms,

$$
\omega_{j t}=\eta_{j t} \cdot \theta_{j t}
$$

that maintain during period $t$ the price which they previously set in period $t-j$. These "end of period" fractions are useful because they serve as weights in various aggregation contexts throughout the paper. For example, the perfect price level index is given by

$$
P_{t}=\left[\sum_{j=0}^{J-1} \omega_{j t} \cdot\left(P_{t-j}^{*}\right)^{1-\varepsilon}\right]^{\frac{1}{1-\varepsilon}}
$$

in this economy. The "beginning of period" fractions are mechanically related to the "end of period" fractions:

$$
\theta_{j+1, t+1}=\omega_{j t} \text { for } j=0,1, \ldots, J-1 .
$$

Time dependent models: If the adjustment fractions $\eta_{j}$ are treated as fixed through time, as in our analysis of section 5.1 below, then Figure 4.1 summarizes the mechanics of models of randomized price-setting opportunities like those time-dependent models developed by Calvo [1983] and Levin [1991]. ${ }^{14}$ In this interpretation, $\eta_{j}$ plays two roles: it is the fraction of firms given the opportunity to adjust within a period and it is also the probability of an individual firm being allowed to adjust after $j$ periods, conditional on not having adjusted for $j-1$ periods.

State dependent models: When we consider state dependent pricing in section 5.5 below, we employ randomized fixed costs of adjustment to induce discrete adjustment by individual firms, while allowing for an adjustment rate that responds smoothly to the aggregate state of the economy.

But in both the time dependent and state dependent settings the firm's optimal pricing decision can be described using a dynamic programming approach. Since it must choose between continuing with a fixed nominal price, which implies a relative price of $p_{t}$, and paying a fixed cost of adjusting its price $(\xi)$, the representative firm solves

$$
v\left(p_{t}, \xi_{t}\right)=\max \left\{\begin{array}{c}
\pi\left(p_{t}\right)+\beta E_{t} \frac{\lambda_{t+1}}{\lambda_{t}} v\left(p_{t} \frac{P_{t}}{P_{t+1}}, \xi_{t+1}\right), \\
\max _{p_{t}^{*}}\left[\pi\left(p_{t}^{*}\right)+\beta E_{t} \frac{\lambda_{t+1}}{\lambda_{t}} v\left(p_{t}^{*} \frac{P_{t}}{P_{t+1}}, \xi_{t+1}\right)\right]-w_{t} \xi_{t}
\end{array}\right\},
$$

where $\frac{\lambda_{t+1}}{\lambda_{t}}$ is the ratio of future to current marginal utility and is the appropriate discount factor for future real profits. The relative price of a firm that last set its price $j$ periods ago would be $p_{t}=\left(P_{t-j}^{*} / P_{t}\right)$ and real profits are given by $\pi\left(p_{t}\right)=\left(p_{t}\right) \cdot d_{t}-\psi_{t} \cdot d_{t}=$

\footnotetext{
${ }^{14}$ Calvo assumes that $\eta_{j}=\eta$, whereas Levin allows $\eta_{j}$ to depend on $\mathrm{j}$, as we do below.
} 
$\left[\left(p_{t}\right)^{1-\varepsilon}-\psi_{t} \cdot\left(p_{t}\right)^{-\varepsilon}\right] d_{t} \cdot{ }^{15}$ For the state dependent setting, a smooth macro model is obtained in Dotsey, King and Wolman [1999] by assuming that there is a continuous distribution of finite fixed menu costs of changing prices across a large number of firms. In the time dependent case, the fixed cost is either zero or infinite depending on when the firm last changed its price.

The dynamic program (4.5) implies that the optimal price satisfies an Euler equation that involves balancing pricing effects on current and expected future profits. That is, as part of an optimal plan, firms that reset their price will choose a price that satisfies

$$
0=\frac{\partial \pi\left(p_{t}\right)}{\partial p_{t}^{*}}+\beta E_{t} \frac{\lambda_{t+1}}{\lambda_{t}} \frac{\partial v\left(p_{t}^{*} \frac{P_{t}}{P_{t+1}}, \xi_{t+1}\right)}{\partial p_{t}^{*}} .
$$

Further, for any given state of the economy there is a unique cutoff price adjustment cost that faces each firm charging a relative price of $p$. All firms that draw an adjustment cost less than this cutoff will optimally choose to adjust their price. Thus, in the state dependent model there will be an endogenous fraction of firms from each vintage, $\left(1-\eta_{j t}\right)$ that will choose to adjust their price. And because all price adjusters face the same dynamic program going forward, they will choose an identical price. Also, as long as the inflation rate is nonzero and the maximum adjustment cost is finite, there will be a maximum number of periods that any firm will leave its price unchanged. Thus the state space for this problem is finite.

Iterating the Euler equation (4.6) forward, the optimal relative price, $p_{t}^{*}$, can be written as an explicit function of current and expected future variables:

$$
p_{t}^{*}=\frac{\varepsilon}{\varepsilon-1} \frac{\sum_{j=0}^{J-1} \beta^{j} E_{t}\left\{\left(\omega_{j, t+j} / \omega_{0, t}\right) \cdot\left(\lambda_{t+j} / \lambda_{t}\right) \cdot \psi_{t+j} \cdot\left(P_{t+j} / P_{t}\right)^{\varepsilon} \cdot d_{t+j}\right\}}{\sum_{j=0}^{J-1} \beta^{j} E_{t}\left\{\left(\omega_{j, t+j} / \omega_{0, t}\right) \cdot\left(\lambda_{t+j} / \lambda_{t}\right) \cdot\left(P_{t+j} / P_{t}\right)^{\varepsilon-1} \cdot d_{t+j}\right\}},
$$

where $\left(\omega_{j, t+, j} / \omega_{0, t}\right)=\left(\eta_{j, t+j} \cdot \eta_{j-1, t+j-1} \cdot \ldots \cdot \eta_{1, t+1}\right)$ is the probability of non-adjustment from $t$ through $t+j$. The pricing rule (4.7) is a natural generalization of the type derived in timedependent settings with exogenous adjustment probabilities that are constant through time as in Calvo [1983] (see for example King and Wolman [1996] and Yun [1996]). According to (4.7), the optimal relative price is a fixed markup over real marginal cost $\left(p^{*}=\frac{\varepsilon}{\varepsilon-1} \psi\right)$ if real marginal cost and the price level are expected to be constant over time. More generally, (4.7) illustrates that the optimal price varies with current and expected future demands, aggregate price levels, real marginal costs, discount factors, and adjustment probabilities. All except the last are also present in time-dependent models. Intuitively, firms know that the price they set today may also apply in future periods, so the expected state of the economy in

\footnotetext{
${ }^{15}$ In writing out the problem we have, for convenience, suppressed explicit notation of the state of the economy. John and Wolman [2000] show that there is a unique bounded function $v(p, \xi)$ that satisfies 4.5.
} 
those future periods affects the price that they choose today. If, for example, marginal cost is expected to be high next period a firm will set a high price in the current period, so as not to sell at a loss next period. Similarly, if demand is expected to be high next period, the firm will set a higher price today so that one period of inflation leaves it closer to maximizing static profits next period. The conditional probability terms $\left(\omega_{j, t+, j} / \omega_{0, t}\right)$ are present in timedependent models, but they are not time-varying. In our setup, these conditional probability terms effectively modify the discount factor in a time-varying manner: a high probability of adjustment in some future period leads the firm to set a price that heavily discounts the effects on profits beyond that period.

Dotsey, King and Wolman [1999] discuss how the price setting (4.7) and price level (4.3) may be loglinearly approximated around a zero inflation steady state to generate expressions that specialize to (3.2) and (3.1) when the probability of price fixity is exogenous, constant over time, and equal to $\eta^{j}$ at horizon $j$. So our simple model of section 3 is in the spirit of the approach that we take in the remainder of the paper.

\subsection{Materials input, marginal cost, and aggregation}

We now turn to detailed development of the materials input linkages in our model. We have previously outlined the effects of material inputs on marginal cost in section 2 above, so that the current discussion concentrates on the microeconomic structure of materials input linkages and aggregation with materials inputs.

\subsubsection{Microeconomic structure of materials}

We think of all firms as buying units of the materials aggregate $x$ from an "intermediary" who assembles these from the products of individual firms of various types. We assume that this firm has technology

$$
x_{t}=\left[\sum_{j=0}^{J-1} \omega_{j t} b_{j t}^{\vartheta}\right]^{\frac{1}{\vartheta}}
$$

where $b_{j t}$ is the amount of product $j$ that the intermediary demands from each firm of type $j$. Cost minimization on the part of the intermediary leads to

$$
b_{j t}=\left[\frac{P_{j t}}{P_{x t}}\right]^{\frac{1}{\vartheta-1}} x_{t}
$$

and

$$
P_{x t}=\left[\sum_{j=0}^{J-1} \omega_{j t} P_{j t}^{\frac{\vartheta}{\vartheta-1}}\right]^{\frac{\vartheta-1}{\vartheta}}
$$


We also assume that the materials aggregator has the same demand elasticities as the consumption and investment aggregators ( so that $-\varepsilon=\frac{1}{\vartheta-1}$ ): a simple story is that all consumers and investors desire the same final good assembled by the intermediary. This assumption also implies that $P_{x t}=P_{t}$. Hence, the microeconomic model delivers the implication - used above in our analysis of marginal cost - that the relative price $P_{x t} / P_{t}$ is constant.

\subsubsection{Aggregation}

If firms of type $j$ purchase quantity $x_{j t}$ of the materials aggregate, then the intermediary's resource constraint is

$$
x_{t}=\left[\sum_{j=0}^{J-1} \omega_{j t} x_{j t}\right]
$$

and its total expenditure $\left[\sum_{j=0}^{J-1} \omega_{j t} P_{j t} b_{j t}\right]=P_{x t} x_{t}=P_{x t}\left[\sum_{j=0}^{J-1} \omega_{j t} x_{j t}\right]$.

All firms of type $j$ will have total demand given as

$$
b_{j t}+c_{j t}+i_{j t}=y_{j t}^{g}=G\left(x_{j t}, n_{j t}, k_{j t}^{s}\right)
$$

Notice that $x_{j t}$ is the local demand for the materials aggregate, while $b_{j t}$ is the materials demand for the local product.

Under constant returns to scale and global factor markets, we can define aggregate gross output as in Yun [1996] and, because all firms choose the same factor input ratios, it is consistent with an aggregate gross output production function.

$$
y_{t}^{g}=\left[\sum_{j=0}^{J-1} \omega_{j t} y_{j t}^{g}\right]=G\left(x_{t}, n_{t}, k_{t}^{s}\right)
$$

However, this real quantity does not correspond to national output measures. To obtain these, we want to net out materials to generate an aggregate measure of value-added. To this end, adding up across all of the markets, we get that

$$
\sum_{j=0}^{J-1} \omega_{j t}\left[P_{j t}\left(c_{j t}+i_{j t}\right)\right]=\left[\sum_{j=0}^{J-1} \omega_{j t} P_{j t}\left(y_{j t}^{g}-b_{j t}\right)\right]=\left[\sum_{j=0}^{J-1} \omega_{j t} P_{j t} y_{j t}^{g}\right]-P_{x t} x_{t}
$$

where the right-hand side is the desired measure of nominal value added. To express this in real terms, we can divide through by the perfect price index and use the aggregation properties of demand

$$
c_{t}+i_{t}=\left[\sum_{j=0}^{J-1} \omega_{j t} p_{j t} y_{j t}^{g}\right]-x_{t}
$$


so that one way to measure aggregate real value-added is as consumption plus investment.

More conventionally, looking at the firms' payments, we have

$$
\sum_{j=0}^{J-1} \omega_{j t}\left[p_{j t} y_{j t}^{g}-x_{j t}\right]=\sum_{j=0}^{J-1} \omega_{j t}\left[w_{t} n_{j t}+q_{t} k_{j t}^{s}+\pi_{j t}\right]
$$

so that aggregate value-added can also be described as a sum of wages plus capital income plus profits.

Finally, actual gnp calculations in the U.S. and other countries more closely resemble the adding up of gross output less materials expenditures. For nominal gnp in our economy, this would be:

$$
Y_{t}=\left[\sum_{j=0}^{J-1} \omega_{j t}\left(P_{j t} y_{j t}^{g}-P_{t} x_{j t}\right)\right]
$$

and for real gnp at benchmark relative prices of unity this would be:

$$
\bar{y}_{t}=\left[\sum_{j=0}^{J-1} \omega_{j t}\left(y_{j t}^{g}-x_{j t}\right)\right]=G\left(x_{t}, n_{t}, k_{t}^{s}\right)-x_{t}
$$

An implicit price deflator would then derive from $Y_{t}=\bar{P}_{t} \bar{y}_{t}$, so that $c_{t}+i_{t}=\left(\bar{P}_{t} / P_{t}\right) \bar{y}_{t}$. For

our quantitative economies, though, we find small variation in $\left(\bar{P}_{t} / P_{t}\right)$. Hence, while we use $c_{t}+i_{t}$ to measure variations in real output, there would be small differences if we looked at $\bar{y}_{t}$.

\subsection{Factor Supply}

In our model economy, we allow aggregate labor input to vary at both the extensive and intensive margins, which can make the supply of labor services quite elastic. We also allow for variable utilization of capital, which can in turn make the supply of capital services fairly elastic. The following two subsections describe the key features of these supply-side mechanisms.

\subsubsection{Supply of Labor}

In order to build a model in which some potential labor suppliers work while others do not, we assume that each of a continuum of agents faces a random discrete cost of going to work, which may be high or low in any particular period. To avoid having to carry along a distribution of wealth, we assume that these risks are fully pooled.

The labor supply behavior of the economy can then be studied by looking at a large household, which maximizes 


$$
\max _{c_{t}^{e}, c_{t}^{h}, e_{t}, l_{t}}\left\{\sum_{t} \beta^{t}\left[\left(e_{t} u\left(c_{t}^{e}, l_{t}\right)+\left(1-e_{t}\right) u\left(c_{t}^{o}, 1\right)\right]\right\}\right.
$$

subject to: $\left[e_{t} c_{t}^{e}+\left(1-e_{t}\right) c_{t}^{h}+\varphi\left(e_{t}\right)+k_{t+1} \leq\left[e_{t} w_{t}\left(1-l_{t}\right)+\pi_{t}\right]+q_{t} k_{t}^{s}-i_{t}\right.$

where $e$ is the fraction of household members that participate in the work force, $c^{e}$ is the consumption of workers, $l$ is the leisure of workers, $c^{o}$ is the consumption of nonworkers, $\varphi$ is a strictly increasing cost function of going to work, $w$ is the wage rate, $\pi$ are total profits remitted by household owned firms, $q$ is the rental rate on capital services, $k^{s}$, and $i$ is the amount of investment expenditure.

The utility function is of the class of functions discussed in King and Rebelo (1999). Specifically,

$$
u(c, l)=(1 /(1-\sigma))\left[c^{1-\sigma} v(1-h)^{1-\sigma}-1\right]
$$

where hours per employed worker are $h=1-l$. Basu and Kimball (2000) explore the usefulness of this class of utility functions for matching both long run properties of consumption and leisure as well as for providing a better fit for cyclical consumption behavior. We parameterize both the function $\varphi$, which governs the responsiveness of labor effort, and the function $v$, which controls the elasticity of labor at the intensive margin to match the empirical work in Mulligan(1998). We also perform experiments where we alter these elasticities.

\subsubsection{Capital use and accumulation}

For simplicity, we think of households owning the stock of capital and renting its services to firms at rental rate $q_{t}$. The household's income from renting services is $q_{t} k_{t}^{s}=q_{t} z_{t} k_{t}$, where $z_{t}$ is the utilization rate.

The law of motion for the capital stock is given by

$$
k_{t+1}=\left(1-\delta\left(z_{t}\right)\right) k_{t}+\mu\left(i_{t} / k_{t}\right) k_{t}
$$

which reflects two influences. First, a higher utilization rate raises the depreciation rate on capital, i.e., $\delta(z)$ is a positive, increasing and convex function of the utilization rate. Second, there are costs associated with the rapid accumulation of capital: $\mu$ is positive and increasing in $i / k$ but there are diminishing returns ( $\mu$ is concave). We have explored the effects of two different models of investment adjustment costs, one in which the adjustment costs apply to gross investment, as exposited here, and the other in which they apply to net investment, so that the accumulation equation is modified to $k_{t+1}=\left[1-\delta\left(z_{t}\right)\right] k_{t}+\mu\left[\frac{i_{t}}{k_{t}}-\delta\left(z_{t}\right)\right] k_{t}$. 
It is useful to break the efficiency conditions into two parts: (i) those which govern labor and consumption; and (ii) those which govern investment, utilization and capital accumulation.

Efficient work effort, participation, and consumption decisions require the following four conditions, in which $\lambda_{t}$ is the Lagrange multiplier on the household budget constraint. First, the marginal utility of consumption by participating individuals and by non-participating workers must be equated to the multiplier, as a condition of efficient risk-sharing. Second, hours per employed worker $\left(h_{t}\right)$ are governed by the familiar requirement that the marginal value of foregone leisure must be equal to the value of working. Third, the rate of participation $\left(e_{t}\right)$ is governed by the requirement that the utility cost of adding the marginal entering worker must just be matched by the gain in terms of additional income, which is $w h$ less the consumption costs of going to work.

$$
\begin{gathered}
\left(c_{t}^{e}\right)^{-\sigma} v\left(1-h_{t}\right)^{1-\sigma}=\lambda_{t} \\
\left(c_{t}^{o}\right)^{-\sigma} v(1)^{1-\sigma}=\lambda_{t} \\
\left(c_{t}^{e}\right)^{1-\sigma} v(1-h)^{-\sigma} v^{\prime}(1-h)=\lambda_{t} w_{t} \\
(1 /(1-\sigma))\left[-\left(c_{t}^{o}\right)^{1-\sigma} v(1)-\left(c_{t}^{e}\right)^{1-\sigma} v\left(1-h_{t}\right)^{1-\sigma}\right]=\lambda_{t}\left[w_{t} h_{t}-\left(c_{t}^{e}-c_{t}^{h}\right)-\varphi^{\prime}\left(e_{t}\right)\right]
\end{gathered}
$$

Taken together, these expressions determine a level of labor supply,

$$
n_{t}=h_{t} e_{t}
$$

that contains variations on both the intensive and extensive margins.

An efficient utilization rate equates the benefits of additional capital services, $q_{t}$, with the cost of replacing the worn out capital stock $\nu_{t} \delta^{\prime}\left(z_{t}\right)$, where $\nu_{t}$ is the Lagrange multiplier on the capital accumulation constraint. As in many investment models, notably that of Hayashi [1982], an efficient rate of investment equates the current cost of the investment good $\lambda_{t}$ to the value of the change in the capital stock resulting from the additional investment $\left(\nu_{t} \phi^{\prime}\left(i_{t} / k_{t}\right)\right)$. Finally, an efficient capital accumulation places restrictions on how capital's shadow price $\nu_{t}$ evolves over time.

$$
\begin{gathered}
q_{t} \lambda_{t}=\nu_{t} \delta^{\prime}\left(z_{t}\right) \\
\lambda_{t}=\nu_{t} \mu^{\prime}\left(i_{t} / k_{t}\right) \\
\nu_{t}=\beta E_{t} \nu_{t+1}\left\{\left[\left(1-\delta\left(z_{t+1}\right)\right)+\mu\left(i_{t+1} / k_{t+1}\right)\right]-\left[\left(i_{t+1} / k_{t+1}\right) \mu^{\prime}\left(i_{t+1} / k_{t+1}\right)+\delta^{\prime}\left(z_{t+1}\right) z_{t+1}\right]\right\}
\end{gathered}
$$

Our introductory model simply assumed that $\log \left(q_{t} / q\right)=\xi \log \left(z_{t} / z\right)$. Approximating the 
first of these efficiency conditions, yields $\log \left(q_{t} / q\right)=\xi \log \left(z_{t} / z\right)+\left[\log \left(\nu_{t} / \nu\right)-\log \left(\lambda_{t} / \lambda\right)\right]$.with $\xi=z \delta^{\prime \prime} / \delta^{\prime}$ so that $\xi$ is linked to the rate at which depreciation costs rise with use. Similarly, approximating the second efficiency condition yields

$$
\log \lambda_{t} / \lambda=\log \nu_{t} / \nu+\frac{(i / k) \mu^{\prime \prime}}{\mu^{\prime}}\left[\log \left(i_{t} / i\right)-\log \left(k_{t} / k\right)\right]
$$

This indicates that our introductory model's approximation may not be too bad if investment adjustment costs are small, in the sense that $\mu$ is nearly linear in $i / k$.

\subsection{Calibration}

The calibration of many of the model's parameters is fairly standard. This section therefore concentrates on elements that are novel to this investigation.

Labor ratios: The parameters of the household's preferences and its cost of going to work function were set to achieve a participation rate of seventy percent $(e=.70)$ and the average hours per population member was twenty percent of available time (based on King, Plosser and Rebelo [1988] calculations). This implies that steady state hours per worker was .29 of available time.

Consumption smoothing: We assume that $\sigma=3$, which involves less intertemporal substitution than the log utility specification that is frequently employed in the literature. The idea that there is less substitution or more risk aversion than log utility is supported by many empirical studies.

Utilization and investment adjustment costs: Elasticity of marginal depreciation costs, $\xi=z \delta^{\prime \prime} / \delta^{\prime}$, set equal to unity based on Basu and Kimball [1997]. ${ }^{16}$

Production function share parameters: We set the steady state ratio of materials inputs to gross output $x / y^{g}=2 / 3$ and labor's share of value-added to two thirds.

Production function elasticities: Various empirical studies suggest that there is a small elasticity of substitution between materials inputs and value-added, so we make the benchmark elasticity of substitution equal one-tenth (close to fixed proportions). We follow many studies in assuming the benchmark model has unit elasticity of substitution between labor and capital, i.e., that it is Cobb-Douglas.

\footnotetext{
${ }^{16}$ We also make investment adjustment costs apply to net rather than gross investment. The practical effect of adjustment costs applied to gross investment is to make marginal costs rise with utilization for another reason besides the depreciation mechanism studied in the current analysis.
} 


\section{Persistence in the fully articulated model}

In this section, we discuss how the fully articulated economy responds to the same sort of monetary disturbance discussed previously in the simple model economy of section 3 .

\subsection{Price stickiness}

For most of this section we assume that price adjustment is time dependent, specifically that there is exogenous price stickiness of the form shown in Table 5.1. The degree of price rigidity is described by the nonadjustment rates $(\eta)$ and stationary fractions $(\omega)$. In our setting, no firm holds its price fixed for more than four periods $(J=4)$ and some adjust more frequently. One way to more precisely gauge the degree of price stickiness is to calculate the average age of a price in the economy at the end of each period, $\omega_{0} 1+\omega_{2} 2+\omega_{3} 3+\omega_{4} 4$. Using the numbers in Table 5.1, this average is 1.98 , so that a random visit to a firm in the economy would conclude that it had a two quarter old price. In a Tayloresque model, such as those studied by Chari, Kehoe and McGrattan [2000], our specification would be similar to a $J=3$ model since that would deliver a nearly identical average price age (since $\left.\frac{1}{3}(1+2+3)=2\right)$. In assessing the degree of price stickiness associated with this number, it is important to stress that our simulations of the simple and fully articulated models assume that $p^{*}$ is set after the monetary shock takes place. Thus, there is complete neutrality if prices are fixed for one quarter.

\section{Table 5.1}

$\begin{array}{lll}j & \text { Nonadjustment Rate }(\eta) & \text { Stationary Fraction }(\omega) \\ 0 & & .41 \\ 1 & .73 & .30 \\ 2 & .62 & .19 \\ 3 & .45 & .10\end{array}$

The nonadjustment probabilities in Table 5.1 are related to other numbers involved in a firm's price setting. These numbers are the probabilities that a currently adjusting firm attaches to the time that its price will be fixed: the probability of holding the price fixed for exactly one period is $\left(1-\eta_{1}\right)$; for exactly two periods is $\eta_{1}\left(1-\eta_{2}\right)$, for exactly three periods 
is $\eta_{1} \eta_{2}\left(1-\eta_{3}\right)$ and for exactly four periods is $\eta_{1} \eta_{2} \eta_{3}$. Thus, the expected duration of price stickiness may be shown to be 2.41 quarters in our model. ${ }^{17}$

These numbers were obtained from assuming-as in Dotsey, King and Wolman [1999]a particular distribution function for adjustment costs as well as a steady state inflation rate of $.3 \%$ (three-tenths of one percent per year). This distribution involves a maximum adjustment cost parameter implying that the highest cost faced by a firm adjusting its price is just over .01 percent of its quarterly wage bill (one-one hundredth of a percent of its wage costs). Given the small steady state inflation rate, these very small adjustment costs were enough to produce a price distribution spread out over a year as displayed in Table 5.1.

In the simple model of section 3, we used the Calvo adjustment specification, in which there is a probability of adjustment that is constant through time and with respect to length of time since last price adjustment. ${ }^{18}$ Wolman [2000] has shown that there can be important quantitative differences in the dynamics of inflation when one uses a rising marginal probability of price adjustment and a maximum period of price fixity, each of which seems more realistic to us than the Calvo specification. Our strategy is to initially fix the $\omega^{\prime} s$ at their steady state levels, exploring time-dependent pricing models in sections 5.2 and 5.3. We then turn to a fully state dependent pricing model in section 5.5 below.

\subsection{Persistence under the standard view}

Figure 5.1 highlights the fact that there is only a small impact effect of money on real activity and there is little persistence in real economic activity, when marginal cost is governed by the standard view. This is a special case of our model in this section which abstracts from materials inputs and capacity utilization. It also uses a relatively small labor elasticity

${ }^{17}$ This can be easily computed, as follows:

$$
\begin{aligned}
D & =\left(1-\eta_{1}\right)+2 * \eta_{1}\left(1-\eta_{2}\right)+3 * \eta_{1} \eta_{2}\left(1-\eta_{3}\right)+4 * \eta_{1} \eta_{2} \eta_{3} \\
& =\left[1-\frac{\omega_{1}}{\omega_{0}}\right]+2 *\left[\frac{\omega_{1}}{\omega_{0}}-\frac{\omega_{2}}{\omega_{0}}\right]+3 *\left[\frac{\omega_{2}}{\omega_{0}}-\frac{\omega_{3}}{\omega_{0}}\right]+4 * \frac{\omega_{3}}{\omega_{0}} \\
& =1+\frac{\omega_{1}}{\omega_{0}}+\frac{\omega_{2}}{\omega_{0}}+\frac{\omega_{3}}{\omega_{0}}=\frac{1}{\omega_{0}}
\end{aligned}
$$

${ }^{18}$ We are building in somewhat more price stickiness than we did in our simple model above. For that economy, the average age of a price was two quarters and the average duration of price fixity was also two quarters. In the Calvo model, the average age of a price is found as

$$
S=(1-\eta)\left[1+2 \eta+3 \eta^{2}+\ldots\right]=\frac{1}{1-\eta}
$$

and the expected duration of newly set price may be found using the same recipe as the previous footnote and using the fact that $\omega_{0}=(1-\eta)$. Hence, it is the same as the average age of the price in the Calvo model. 
with respect to the wage (of .4), which is suggested by empirical evidence pertaining to the response of man-hours on the intensive margin. This replicates the findings of Chari, Kehoe and McGrattan [2000] for our time-dependent specification of price stickiness with weights from Table 5.1.

The price level moves substantially on impact (an increase of over .8) even though only $41 \%$ of the firms are adjusting). The amount of price level movement occurs because price adjusting firms choose to raise their prices more than one-for-one with the money stock. In terms of the dynamics of output, the impact effect is 0.19 and the total multiplier is .39. The mean lag is 1.86 quarters, which is not too different from what was produced by our simple model of section 3 .

Also, with this parameterization, the production structure requires that labor input is substantially more volatile than output. The real rental rate, the real wage rate and real marginal cost rise dramatically in response to the monetary disturbance: the 0.19 percent increase in output and the .3 percent increase in labor input lead to a rise in real marginal cost that is over one percent. Hence, an initial rise in real marginal cost and an initial interval of high expected inflation motivates firms to raise their prices aggressively. Those firms which can adjust their price do so by nearly the full amount of the long-run two percent increase, as shown by the $P^{*}$ series in the final panel of Figure 5.1

The fully articulated model involves an explicit decomposition of output into investment and consumption. In this simulation, investment adjustment costs are set equal to zero so as to generate an impact effect on investment that is three times the impact effect on consumption. In this regard, we are following the spirit - but not the details - of the approach taken in CKM [2000]. ${ }^{19}$ Because the output effects of the disturbance are largely transitory, it is not too surprising that these mainly affect investment, since the permanent income theory suggests that consumption should be smoothed. In our fully articulated model, though, the nonseparable nature of preferences over consumption and leisure means that individuals demand more consumption during periods of high work, given wealth and intertemporal substitution effects associated with changes in the path of real interest rates. ${ }^{20}$ That is, our model contains the mechanisms which Baxter and Jermann [1999] and Basu and Kimball [2000] have suggested explain apparent "excess sensitivity" of consumption to

\footnotetext{
${ }^{19}$ CKM [2000] specify a quadratic investment adjustment cost model, with costs depending on net investment. They adjust the single free parameter of that specification so that the response of investment relative to output - specifically the relative standard deviation of HP filtered data from the model - matches that in the U.S. data.

${ }^{20}$ The series "basic consumption" graphed in Figure 6.1 shows how consumption responds as a result of wealth and interest rate effects if manhours are fixed. This series plays no other role in this model version.
} 
income over the business cycle.

\subsection{Persistence with real flexibilities}

Figure 5.2 highlights the fact that there is an important impact effect of money on real activity and there is substantial persistence in real economic activity, when marginal cost is based on a supply-side with real flexibilities and using the same degree of exogenous price stickiness. This benchmark model has the following structural characteristics: a materials inputs share of $2 / 3$, variability of capacity utilization (an elasticity of the rental rate to the rental price of unity), and substantial labor supply variation. The larger labor elasticity arises from responses along the extensive margin: specifically, there is a Frisch labor supply elasticity of 2 for total hours, which involves an elasticity of .4 in hours per employed worker and of 1.6 in terms of employment. ${ }^{21}$

Turning to the details shown in Figure 5.2, the price level moves only by about .36 percent in response to a one percent monetary expansion on impact, even though $41 \%$ of the firms are free to adjust their prices. The smaller response exhibited in this setting occurs because price adjusting firms now choose to raise their prices less than one-for-one with the money stock. There is an impact effect on real output of .64 percent and a total multiplier of 3.6, which is distributed over eight quarters. The elongated impulse response is reflected in a larger mean lag of 2.70, a lag that is similar to the one displayed by the simple model of section 3. More generally, we find that there is a uniform message from the small loglinear and large model with micro-foundations: real flexibilities on the supply side lead to quantitatively large amounts of persistence.

The benchmark model also seems more closely in accord with other aspects of business cycles. All of the factors of production - materials, total hours, and capacity utilization rise roughly one-for-one with output. Materials do so because they have a low substitution elasticity (about one-tenth); hours and capacity utilization do so because they are supplied with substantial and similar elasticities so that little factor substitution takes place even though the value-added production function is Cobb-Douglas. The real rental rate and the real wage rate rise by a similar amount,

Marginal cost moves by one-third as much as the average of the real factor rental rates because the share of value added in total costs is one-third. Judging again from impact effects, the elasticity of real marginal cost with respect to output is about .2 (the impact effect on marginal cost is about .12 and the impact effect on output is about .6). Since

${ }^{21}$ There is, of course, a smaller general equilibrium labor supply elasticity because consumption rises in response to the monetary disturbance. Judging from the relative height of impact effects, this elasticity is slightly greater than unity, because the real wage rises by about .5 while labor and output rises by over .6 . 
real marginal cost does not rise dramatically in response to the monetary disturbance, firms which can adjust their price do so much less aggressively than in the previous experiment.

Turning to the decomposition of output into investment and consumption, investment is again three times as volatile as output on impact since we imposed this in our calibration of (net) investment adjustment. Given that the disturbance is more persistent, there are larger effects on wealth and the path of real interest rates that motivate adjustments in consumption: these channels are reflected in the path of "basic consumption" in our model, which is the consumption of individuals not employed. Total consumption is more responsive to the shock for two related reasons: the marginal utility condition (4.8) mandates that more consumption be allocated to individuals who are either working harder on the intensive margin or moving into employment.

\subsection{A recurrent interest rate puzzle}

In both Figures 5.1 and 5.2, there is substantial expected inflation, which is an inevitable result of short-run price stickiness coupled with a higher long-run path of the price level. The total necessary rise in the price level is about $1.67 \%$, which is distributed over an eight quarter adjustment interval. The extent of expected inflation is highest earliest in the impulse response, so that the upward pressure on the nominal interest rate is greatest at that time. This degree of expected inflation results in a rise in the nominal interest rate in response to expansionary monetary policy. That is: the model fails to produce a liquidity effect in response to this particular monetary disturbance. ${ }^{22}$

\subsection{Persistence with state dependent pricing}

There is considerable persistence with the alternative view of marginal cost even when pricing is state dependent, as is shown in Figure 5.3. This figure is constructed under the assumption that firms face a distribution of real adjustment costs, with small values of the highest adjustment cost as previously discussed.

There are some aspects of the dynamic responses illustrated in Figure 5.3 which are very predictable: there is a smaller impact effect of money on output, (.51 rather than .64), which is consistent with the idea that state dependent pricing is inevitably less sticky than time dependent pricing. There is also a smaller total effect (2.50 rather than 3.40) which is again

\footnotetext{
${ }^{22}$ Keen [2000] explores the extent to which financial market frictions can produce a liquidity effect in combination with sticky prices, as well as reviewing prior literature on this topic. While he imbeds the standard view of marginal cost in his models, it would be interesting to explore the power of liquidity effect mechanisms using our view of marginal cost.
} 
consistent with a smaller amount of stickiness. But there is considerable persistence, as reflected in the total multiplier and a mean lag of 2.68 .

Other aspects of the dynamic responses are less intuitive: there is no longer a "hump shaped" effect of money on output and there are other non-monotonicities in the impulse responses. These findings warrant two observations. First, the smooth impulse responses in the time dependent economy displayed in Figure 5.2 are perhaps surprising themselves: staggered pricing mechanically imparts a moving average structure to dynamics (as displayed in Figure 4.1), but this is smoothed out by the dynamics of the forcing process and the cautious nature of individual pricing responses. Second, in experimentation with models along these lines, we have found that the details of impulse responses in state dependent pricing frameworks are somewhat more fragile than in time dependent frameworks.

While there are some aspects of the state dependent pricing results which warrant further investigation, it is important that a key finding not be overlooked: our production-side mechanisms allow considerable persistence when there is state dependent pricing. Other mechanisms for generating persistence in time dependent models, such as the factor specificities discussed by Kimball [1995] and Rotemberg [1996], may not survive in a state dependent

pricing setting. Kimball and Rotemberg stress that factor specificities mean that firms which currently adjust pricing have low output and low marginal cost, so that they are less aggressive in their price-setting than if factors can flexibly be reallocated. But, symmetrically, firms that are not adjusting prices have high output and high marginal cost: they would pay a great deal to adjust their prices.

\subsection{Robustness to details of production structure}

In this section we investigate how the core components of our "real flexibilities" view contribute to overall persistence. The basic summary statistics on output responses - impact multiplier, total multiplier and mean lag - are displayed in Table 5.2, which also describes the cases and the location of additional figure information. Comparing sum of the lagged responses as well as the mean lag generated by the various perturbations with those of the standard model, one sees that all three core components: materials inputs, elastic labor supply on the extensive margin, and variable utilization of capital contribute to greater persistence. 
Table 5.2:

Summary of Sensitivity Analysis

$\begin{array}{llllll}\text { case } & \text { figure(s) } & \text { description } & \text { impact } & \text { total } & \text { mean } \\ 1 & 5.4 \mathrm{~A} / 5.1 & \text { standard view (CKM) } & .19 & .39 & 1.86 \\ 2 & 5.4 \mathrm{~B} & \text { elastic factors but no materials } & .55 & 2.14 & 1.90 \\ 3 & 5.4 \mathrm{C} & \text { materials with inelastic factors } & .38 & 1.17 & 2.48 \\ 4 & 5.4 \mathrm{D} & \text { materials and elastic labor } & .59 & 2.95 & 2.98 \\ 5 & 5.4 \mathrm{E} & \text { materials and utilization } & .50 & 1.69 & 1.66 \\ 6 & 5.4 \mathrm{~F} / 5.2 & \text { benchmark } & .64 & 3.40 & 2.70 \\ 7 & 5.3 & \text { benchmark (sdp) } & .51 & 2.50 & 2.68 \\ 8 & 5.5 & \text { benchmark (small interest elasticity) } & .96 & 3.82 & 2.38 \\ 9 & 5.6 & \text { benchmark (large interest elasticity) } & 1.39 & 4.39 & 2.02\end{array}$

Additional detail on model implications is provided in Figure 5.4, which graphs output and marginal cost for cases (1-5), building up to the benchmark case 6 that is also displayed in Figure 5.2. Figure 5.4.A is the output and marginal cost responses in the CKM [2000] case that has already been displayed in Figure 5.1 and its parameterization has already been described in the text. Figure 5.4.B. sets the material share equal to zero while retaining labor supply on the extensive margin and variable capacity utilization, with the same elasticities as in the benchmark model: there is a marginal cost elasticity of about .40 in this case. ${ }^{23}$ Figure 5.4.C keeps a materials share of two-thirds, but eliminates labor supply elasticity on the extensive margin and variable capacity utilization: it illustrates why some researchers have thought that reasonable materials input shares would not, by themselves, generate a substantial amount of persistence. ${ }^{24}$ Figure $5.4 \mathrm{D}$ is obtained simply by eliminating variable capital utilization from our benchmark: it shows that the combination of materials input and elastic labor supply can generate a small elasticity of marginal cost with respect to output (about .3) and substantial persistence. But, as we have stressed earlier, the fixed capital stock implies that labor is much more volatile than output in this case. Figure 5.5E displays the case with materials input and utilization, but without labor supply elasticity on the extensive margin. Finally, Figure 5.5F is the benchmark model, also shown in Figure 5.2, that has an elasticity of marginal cost with respect to output of about .2. Taken together, the panels of this figure indicates how each structural feature, in turn, dampens the response of marginal cost to output and, hence, draws out the response of output to a monetary shock.

\footnotetext{
${ }^{23}$ This corresponds to a case that we studied previously in Dotsey, King and Wolman [1997].

${ }^{24}$ For example, it is apparently for this reason that Bergin and Feenstra [2000] are led to explore the influence of demand specifications that differ from the CES form employed here.
} 


\subsection{Interest rates and money demand}

We have seen that a recurrent feature of the model economies displayed in Figures 5.1, 5.2 and 5.3 is the rise in the nominal interest rate when there is a positive monetary injection. Previously, we traced this finding to two properties of the model. First, there is a substantial rise in expected inflation, which must occur because there is short-run price stickiness coupled with a long-run rise in the price level. Second, there are relatively small variations in the real rate of interest.

We now introduce an interest-sensitive money demand function, written in a semilogarithmic form

$$
\log M_{t}-\log P_{t}=\log y_{t}-\zeta R_{t}
$$

We do not derive this relationship from an underlying microeconomic specification of preferences or transactions costs. Instead, our approach relies on the idea explicitly derived movements in monetized exchange typically imply small variations in (i) resource costs of using alternative media and (ii) in substitution effects arising from "wedges of monetary inefficiency." Experiments with many optimizing models of money demand have convinced us that this is a good approximation; it also has the added feature that any consequences of altering the demand for money can be traced directly to its implications for the behavior of aggregate demand, as in the IS-LM model.

To think about the issues, start with our benchmark model in Figure 5.2 that sets the interest sensitivity of money demand $(\zeta)$ equal to zero. In this case, there is a given rise in net output (call it $\log \left(y_{0}^{b}\right)$ ), the price level, and an associated rise in the nominal interest rate (call it $R_{t}^{b}$ ). Now, suppose that we raise $\zeta$ from zero to some positive number: what is wrong with our prior solution? There is now an excess supply of money, because money demand is lower given that the monetary shock raises the nominal interest rate. Hence, any new solution must move in the direction of: (i) a higher output level, so as to raise the real demand for money; (ii) a higher price level, so as to reduce the real supply of money; or (iii) a lower nominal interest rate, so as to raise the real demand for money.

These three responses are all mutually consistent. First, a higher output level automatically increases the demand for money, reducing the excess supply. Second, a higher output level raises real marginal cost and encourages firms to increase their prices, so that there will be a greater rise in the price level. Third, given that there is a higher initial price level, there is less expected inflation which must take place in order to reach the higher long-run price level. In sum, the rise in the nominal rate means that there is an additional aggregate demand stimulus in the model (exactly the opposite of the standard IS-LM model's cushioning of aggregate demand). 
Figures 5.5 and 5.6 illustrate the dynamic effects of a monetary shock in our benchmark model of section 5.2, using values of $\zeta=1$ and $\zeta=8 .^{25}$ These graphs show that the introduction of interest-sensitive money demand has the effects discussed above, yielding a substantially larger impact effect of money on output. Specifically, the impact effects on output and the price level of a one percent monetary change are .95 and .38 in Figure 5.5 with $\zeta_{R}=1$, as compared to the benchmark values of .64 and .36 in Figure 5.2. There is also a smaller rise in the nominal interest rate. With a greater interest-sensitivity $(\zeta=8)$, there are larger effects of money on output and prices as shown in Figure 5.6: here the impact effects are 1.39 and .43 respectively. Since these economies display a small elasticity of marginal cost with respect to output, it is perhaps not too surprising that the bulk of the effect is concentrated on output rather than on prices. This is particularly true because the interest-rate induced changes in the demand for money are transitory relative to the dynamics displayed in Figure 5.2.

Figures 5.5 and 5.6 also show the effect of interest-sensitive money demand on the overall shape and measure of persistence displayed by the impulse response function. For the smaller interest sensitivity shown in Figure 5.5, the total effect is larger (3.8) than for it was for the benchmark case (3.4) shown in Figure 5.2, in which money demand was interest-insensitive. There is however, less persistence with the mean lag falling to 2.38. These conclusions are reinforced for the higher sensitivity, but persistence is not eliminated by interest-sensitive money demand.

The endogenous determination of consumption and investment in the fully articulated model also means that the above discussion, which centered around the money demand function is incomplete: the altered dynamic path of real activity now implies that there is a much larger decline in the real interest rate displayed in Figures 5.5 and 5.6 than was present in Figure 5.2.

\footnotetext{
${ }^{25}$ Our money demand sensitivities are not large as those implicit in CKM [2000], who use an money demand specification with an elasticity of .39 that is identified from the long-run (low frequency) behavior of real balances and the nominal interest rate. The semielasticity $\zeta$ is related to an elasticity $\varepsilon$ via $\zeta=\varepsilon / R$, where $R$ is the stationary interest rate. In our analysis, an annual nominal interest rate of $6 \%$ is a nominal interest rate of $.06 / 4=.015$ per quarter. Hence, $\varepsilon=.39$ corresponds to $\zeta=26$.

We use more modest values, as in King and Watson [1996], because we believe that there is a smaller short-run elasticity of money demand that is pertinent for business cycle analysis. The incorporation of a money demand function with a distinction between short and long-run elasticities into business cycle models is a promising line of research.
} 


\section{Summary and conclusions}

One of the most intensively active areas of macro research over the last decade has been the development of fully optimizing general equilibrium business cycle models that feature imperfect competition and sticky prices. These models of the new neoclassical synthesis can be used to evaluate the influences of monetary shocks and monetary policy rules on economic activity, as real business cycle models were previously used to study the effects of productivity. Early efforts to explore the empirical implications of these sticky price models for the volatility and comovement of nominal and real aggregates, such as that of King and Watson [1996], utilized the standard one sector production function employed in early real business cycle research. These explorations were disappointing, in that simulations from the sticky price models arguably performed much worse than benchmark real business cycle models.

Recently Chari, Kehoe, and McGrattan [2000] have stressed that such models contain a substantial persistence problem. That is, monetary shocks have only transitory effects on real activity effects that do not persist beyond the duration of the exogenously imposed price fixity. In this paper, we trace the persistence problem to the supply side of the standard model, which makes marginal cost highly sensitive to changes in output, thus leading to aggressive price responses by those firms that adjust prices.

We incorporate empirically realistic real flexibilities into the supply side of the macroeconomic model by including important roles for materials inputs, variable capacity utilization, and variation in employment along an extensive margin. These modifications dramatically reduce the elasticity of marginal cost with respect to output and thus lead to more gradual price adjustment, which in turn implies greater persistence in economic activity. There are additional gains to using this more realistic supply side, namely we are able to match other empirical regularities that are at variance with the standard model. For example, our model produces near one-for-one comovement of output, hours, and capacity utilization. This comovement is a direct outgrowth of the real flexibilities view of the production side of the model. In turn this view of production results in the model's ability to generate persistent responses of real activity to monetary shocks.

Having shown the potential importance of supply-side real flexibilities, we think that there is important work to be done on refining estimates of crucial parameters-such as the elasticity of employment response and capacity utilization-as well as exploring the robustness of our results to alternative models of utilization and sectoral interrelationships in production. For example, it seems clear that some materials prices are procyclical but that others are lagging.

Other lines of macroeconomic research also may benefit from incorporating the real flexi- 
bilities view taken in this paper. Some macroeconomists such as Ball and Romer [1990] have added real wage rigidities into macroeconomic models that include nominal price rigidities of the form studied in this paper. We interpret this approach as providing an alternative explanation of why labor input is volatile while real wages are not. But if such approaches are to generate one-for-one comovement of output and hours, then it seems that they must incorporate variable capacity utilization. Further, even if real wage movements are modest, marginal cost can still rise substantially if fixed capital input leads to sharply diminishing marginal products. Variable utilization and variable materials inputs serve to mitigate the effects of a largely predetermined capital stock. Therefore, taking a broader view of production will enhance the empirical properties of models with real wage rigidities.

Given that persistence need not be a problem for this class of models, research on quantitative general equilibrium models can now focus on some other important issues. First and foremost is the puzzling behavior of the nominal interest rate, which rises in response to a positive monetary shock. Thus the model fails to generate a liquidity effect. Although there is some empirical debate concerning the extent of this effect and whether it is time varying (see Gordon and Leeper [1993]), most economists believe that it is a feature of the economy. A crucial ingredient in the model's counterfactual response is that expected inflation rises rapidly. Some increases in expected inflation at some horizons are inevitable because the long run price level rises in response to the shock and the short run price level is fairly sticky. Second, there is broad consensus that central banks use the interest rate rather than a money stock as an instrument. As pointed out in Dotsey [2000a, 2000b], the form of these policy rules has implications for the way the economy responds to monetary policy shocks. It is, therefore, important to investigate whether monetary policy shocks give rise to persistent macroeconomic fluctuations when the central bank is following an interest rate rule. And specifically whether the liquidity effect puzzle carries over to such a setting. Third, we have studied the dynamic effects of monetary policy shocks under the assumption that agents correctly understand the persistent nature of the process generating the money supply and the inflationary objectives of the central bank. In some post-war business cycle episodes this assumption seems inappropriate, so that it appears important to examine dynamic responses using alternative assumptions of expectations formation. Finally, we think that detailed empirical appraisal of this class of models is essential and that the supply-side articulated in this paper may improve their performance as positive models of business cycles. ${ }^{26}$

\footnotetext{
${ }^{26}$ Sims [1997] reccomends the comparison of quantitative model impulse responses with those from estimated vector authoregressions, which is a natural proposal for the models in this paper.
} 


\section{References}

[1] Ball, Laurence and David Romer (1990), "Real Rigidities and the Non-Neutrality of Money," Review of Economic Studies, 57: 183-203

[2] Basu, Susanto, and Miles S Kimball "Cyclical Productivity with Unobserved Input Variation", NBER Working Paper 5915, February 1997.

[3] Basu, Susanto and Miles Kimball "Long-Run Labor Supply and the Ealsticity of Intertemporal Substitution for Consumption", manuscript University of Michigan December 2000 .

[4] Baxter, Marianne and Urban J. Jermann, "Household Production and the Excess Sensitivity of Consumption to Current Income," American Economic Review, September 1999, 902-920.

[5] Bergin, Paul R. and Robert C. Feenstra, "Staggered Price Setting, Translog Preferences, and Endogenous Persistance", Journal of Monetary Economics, vol 45 (June 2000), 657680.

[6] Blanchard, Olivier J. and Charles M. Kahn (1980), "The Solution of Linear Difference Models Under Rational Expectations," Econometrica, 48: 1305-1311.

[7] Blanchard, Olivier J. and Nobuhiro Kiyotaki (1987), "Monopolistic Competition and the Effects of Aggregate Demand," American Economic Review, 77: 647-666.

[8] Bils, Mark, "The Cyclical Behavior of Marginal Cost and Price," The American Economic Review, Vol. 77, No. 5. (Dec., 1987), pp. 838-855.

[9] Burns, Arthur F. and Wesley C.Mitchell, Measuring Business Cycles, National Bureau of Economic Research, 1946

[10] Calvo, Guillermo. "Staggered Prices in a Utility-Maximizing Framework," Journal of Monetary Economics, vol. 12 (September 1983), pp. 383-98.

[11] Clarida, Richard, Jordi Gali, and Mark Gertler. "The Science of Monetary Policy: A New Keynesian Perspective," Journal of Economic Literature, vol. 37 (December 1999), pp. 1661-1707.

[12] Chari, V. V., Patrick J. Kehoe, and Ellen R. McGrattan, "Sticky Price Models of the Business Cycle: Can the Contract Multiplier Solve the Persistence Problem," Econometrica, vol. 68 (September 2000), pp. 1151-79. 
[13] Dotsey, Michael "Structure from Shocks" manuscript Federal Reserve Bank of Richmond, 2000.

[14] Dotsey, Michael "The Importance of Systematic Monetary Policy for Economic Activity," Federal Reserve Bank of Richmond Economic Quarterly, Summer 1999, 41-60.

[15] Dotsey, Michael, Robert G. King, and Alexander L. Wolman, "Menu Costs, Staggered Price Setting, and Elastic Factor Supply," presented at NBER summner institute (monetary economics program), July 1997.

[16] Dotsey, Michael, Robert G. King, and Alexander L. Wolman. "State-Dependent Pricing and the General Equilibrium Dynamics of Money and Output," Quarterly Journal of Economics, vol. 114 (May 1999), pp. 655-90.

[17] Gali, Jordi, and Mark Gertler. "Inflation Dynamics: A Structural Econometric Analysis," Journal of Monetary Economics, vol. 44 (October 1999), pp. 195-222.

[18] Goodfriend, Marvin, and Robert G. King. "The New Neoclassical Synthesis and the Role of Monetary Policy," in Ben Bernanke and Julio Rotemberg, eds., NBER Macroeconomics Annual 199\%. Cambridge, Mass.: MIT Press, 1997, pp. 231-82.

[19] Gordon, David and Eric Leeper, "In Search of the Liquidity Effect," Journal of Monetary Economics, 29 (3), June 1992:341-369.

[20] Hayashi, Fumio J. (1982), “Tobin's Marginal q and Average q: A Neoclassical Interpretation," Econometrica, 50: 215-224.

[21] Kimball, Miles S. "The Quantitative Analytics of the Basic Neomonetarist Model," Journal of Money, Credit, and Banking, vol. 27 (November 1995), pp. 1241-77.

[22] John, Andrew and Alex L. Wolman "Does State Dependent Pricing Imply Coordination Failure",manuscript Federal Reserve Bank of Richmond, 2000.

[23] King, Robert G., "The New IS-LM Model: Language, Logic, and Limits," Federal Reserve Bank of Richmond Economic Quarterly, vol. 86/3, Summer 2000, 45-103..

[24] King, Robert G., Charles I. Plosser, and Sergio T. Rebelo, "Production Growth and Business Cycles: I. The Basic Neoclassical Model," Journal of Monetary Economics, March/May 1988, 195-232. 
[25] King, Robert G. and Sergio T. Rebelo, "Resuscitating Real Business Cycle," in Handbook of Macroeconomics vol 1b Edited by John B. Taylor and Michael Woodford, North Holland , Amsterdam, 1999.

[26] King, Robert G.and Mark W. Watson. "Money, Prices, Interest Rates and the Business Cycle," Review of Economics and Statistics, vol. LXXVIII, (February 1996), pp. 35-53.

[27] King, Robert G. and Alexander L. Wolman, "Inflation Targeting in a St. Louis Model of the 21st Century," Federal Reserve Bank of St. Louis Review, vol. 78 (May/June 1996), pp. $83-107$.

[28] Levin, Andrew (1991), "The Macroeconomic Significance of Nominal Wage Contract Duration," University of California, San Diego Discussion Paper 91-08.

[29] Mulligan, Casey B, "Substitution over Time: Another Look at Life Cycle Labor Supply," NBER Working Paper \#6585, May 1998.

[30] Rotemberg, Julio J., "The New Keynesian Microfoundations," in Stanley Fischer, ed., NBER Macroeconomics Annual 198\%. Cambridge, Mass.: MIT Press, 1987, pp. 63-129.

[31] Rotemberg, Julio J., (1996) "Prices, Output and Hours: An Empirical Analysis Based On a Sticky Price Model," Journal of Monetary Economics, 37: 505-533.

[32] Rogerson, Richard (1988), "Indivisible Labor, Lotteries and Equilibrium," Journal of Monetary Economics, 21: 3-16.

[33] Sargent, Thomas J., Macroeconomic Theory. New York: Academic Press, 1978.

[34] Sims, Christopher A., "Models and their uses," American Journal of Agricultural Economics, 71 (May 1989), 489-94.

[35] Taylor, John B., "Aggregate Dynamics and Staggered Contracts," Journal of Political Economy, vol. 88 (February 1980), pp. 1-23.

[36] Wolman, Alexander L. "Sticky Prices, Marginal Cost, and the Behavior of Inflation," Federal Reserve Bank of Richmond Economic Quarterly, vol. 85 (Fall 1999), pp. 29-48.

[37] Yun, Tack. "Nominal Price Rigidity, Money Supply Endogeneity, and Business Cycles," Journal of Monetary Economics, vol. 37 (April 1996), pp. 345-70. 
Figure 3.1: Dynamics with Standard View
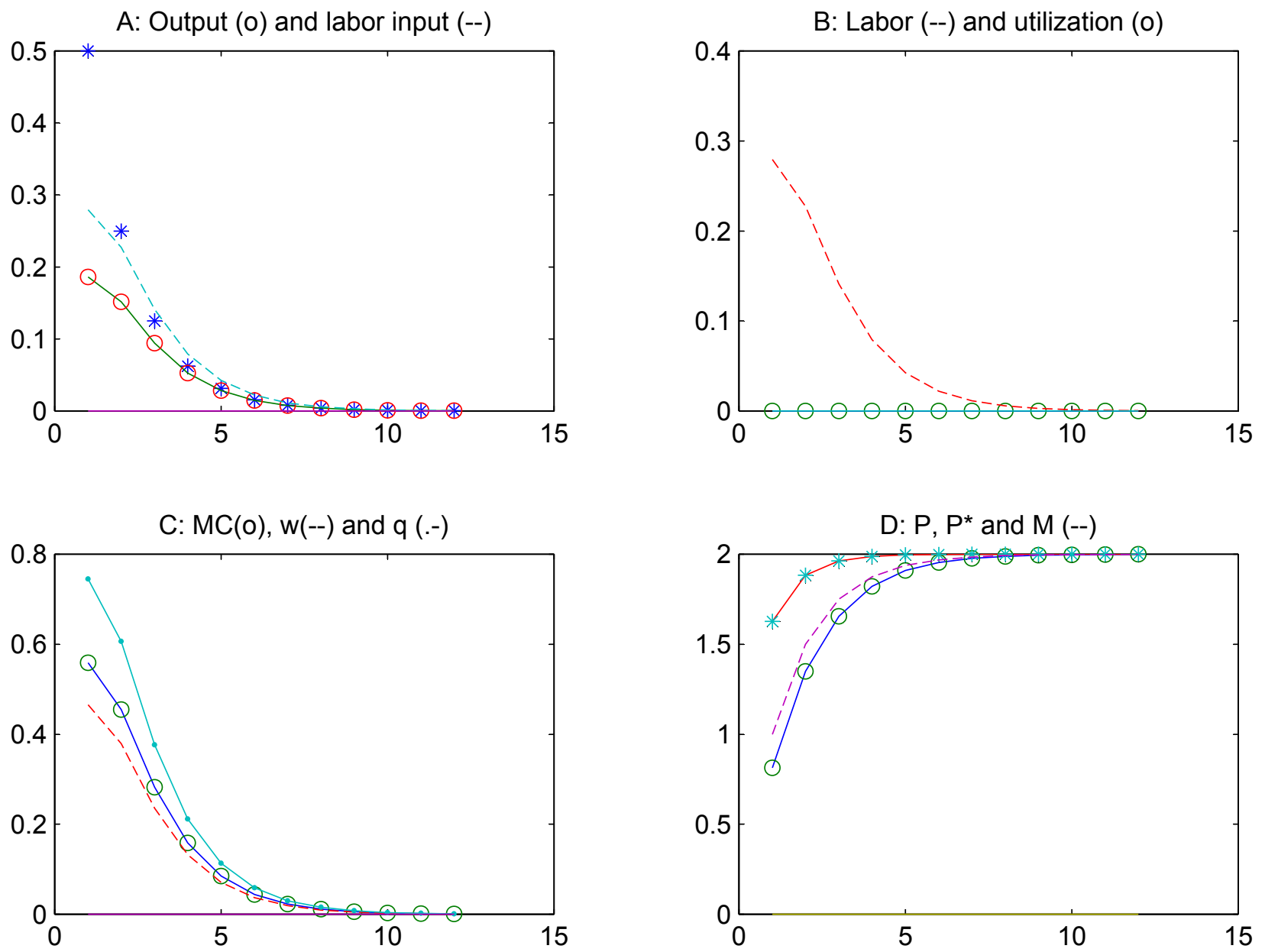
Figure 3.2: Dynamics with Real Flexibilities
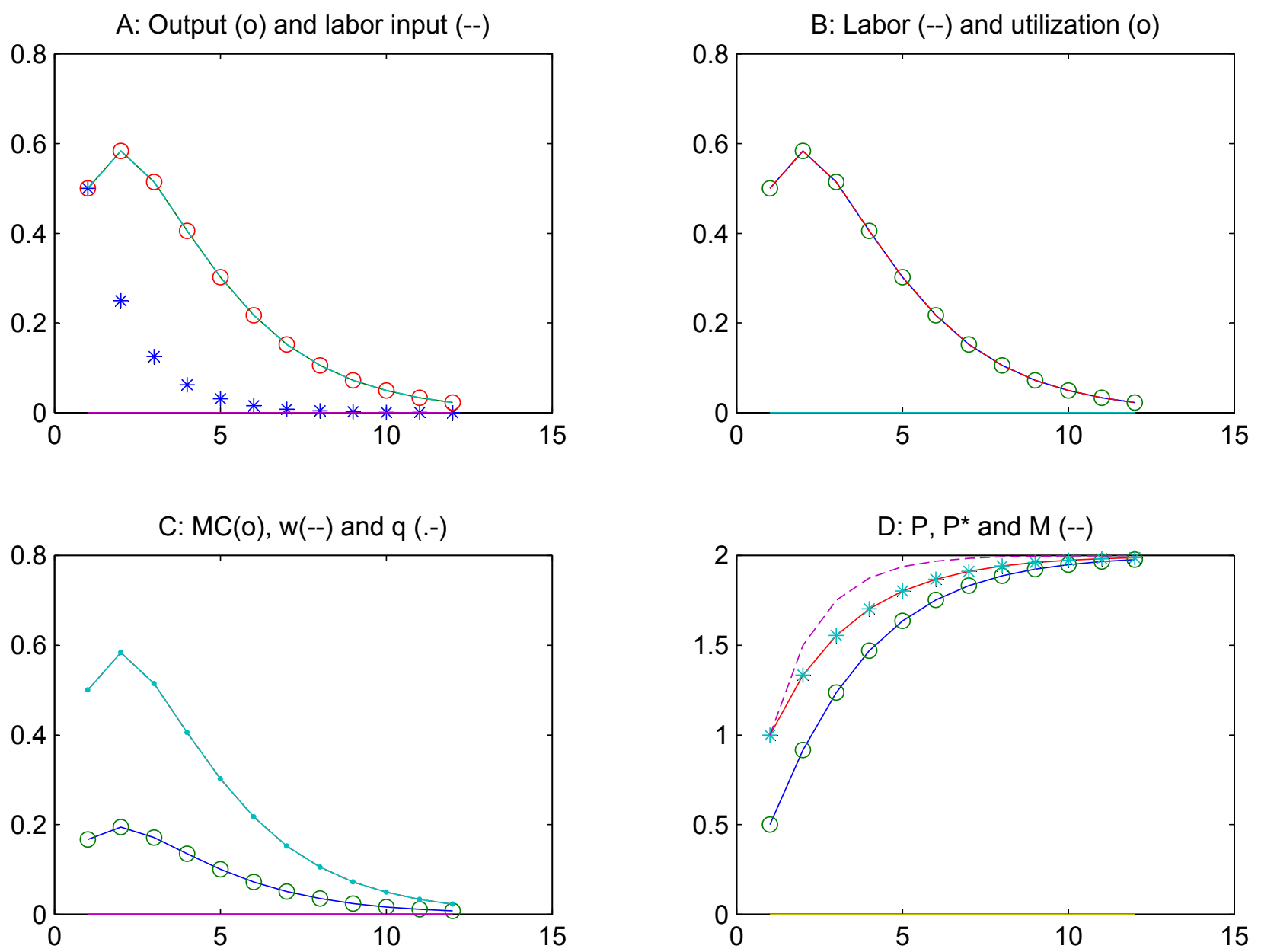
Figure 4.1

Evolution of "vintages" of price-setters

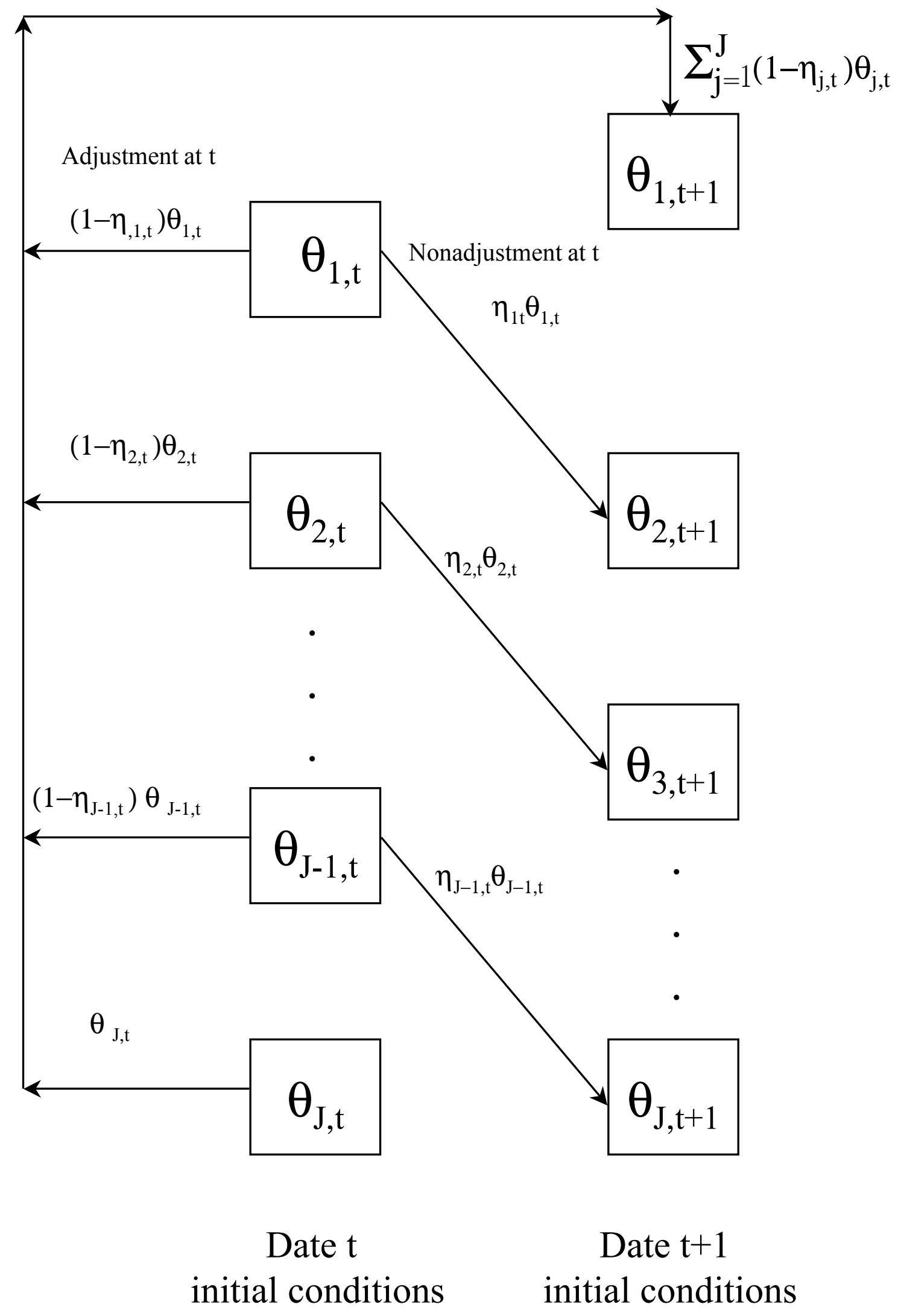




\section{Figure 5.1 CKM Specification}

A: output [o] and labor input [- - ]
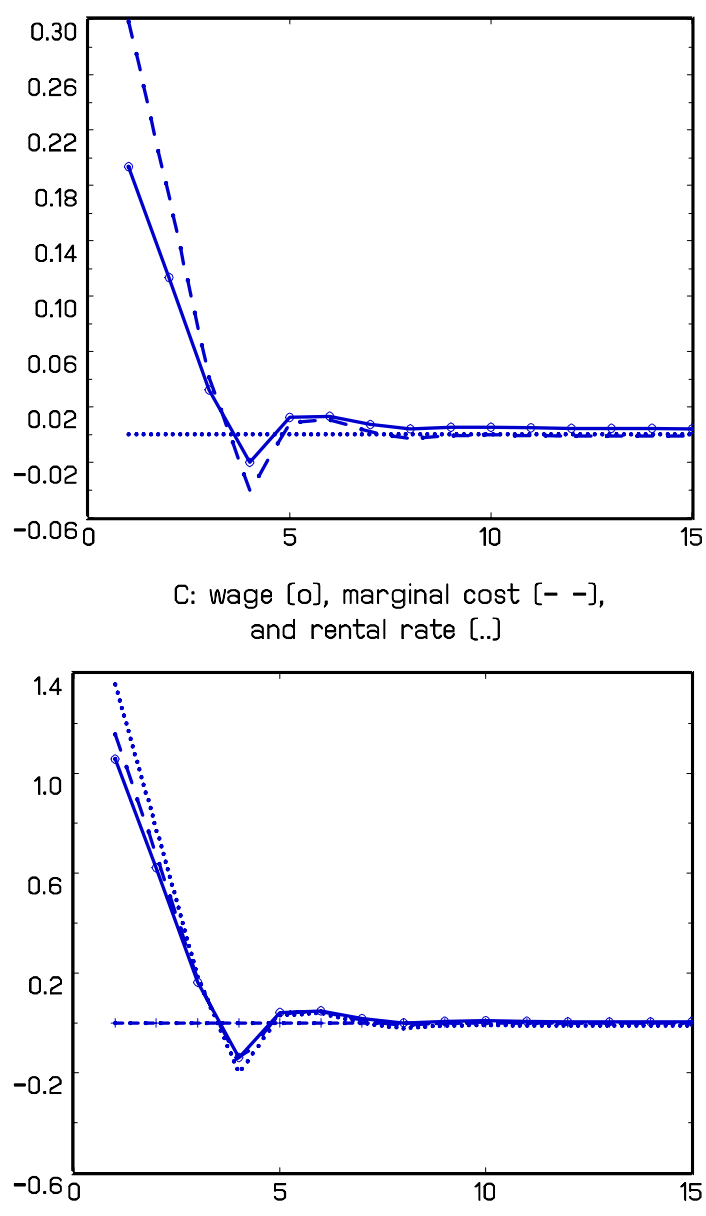

E: total consumption [o], investment [- -], and basic consumption [. .]

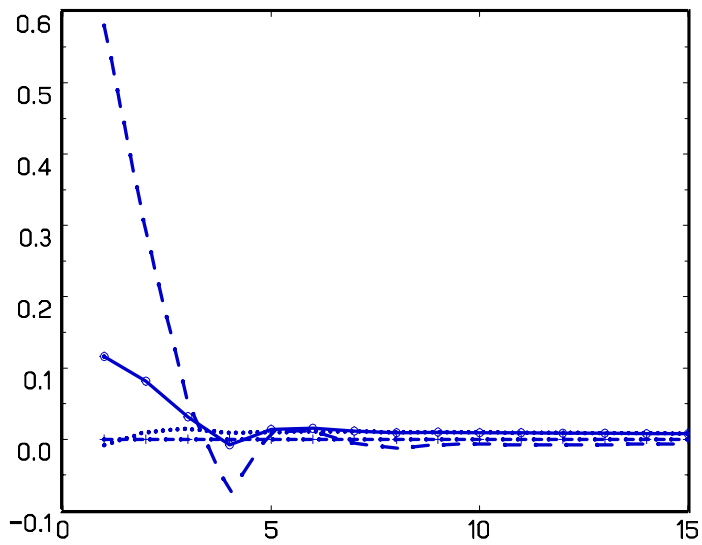

B: participation [o], hours per worker [- - ], and utilization [. .]



$\mathrm{D}: \mathrm{P} *[0]$, price level [- - ], and nominal money stock [. .]
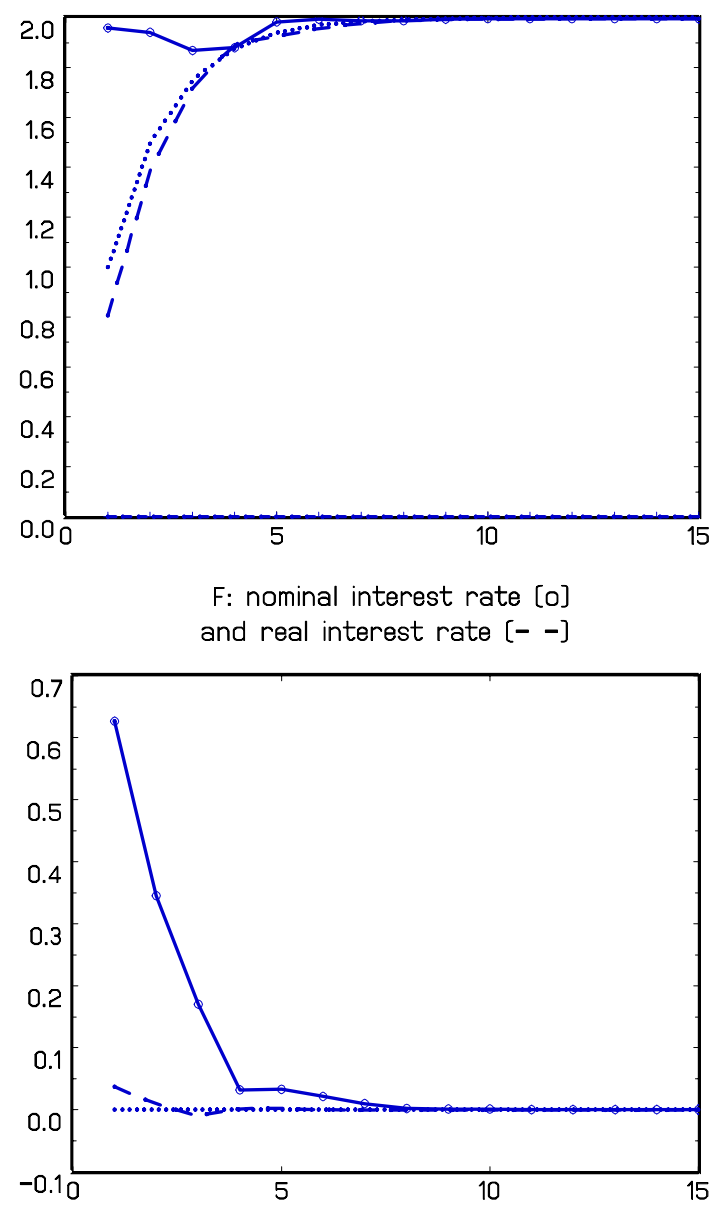
Figure 5.2 Benchmark

A: output [o], labor input [- -], and materials [. .]
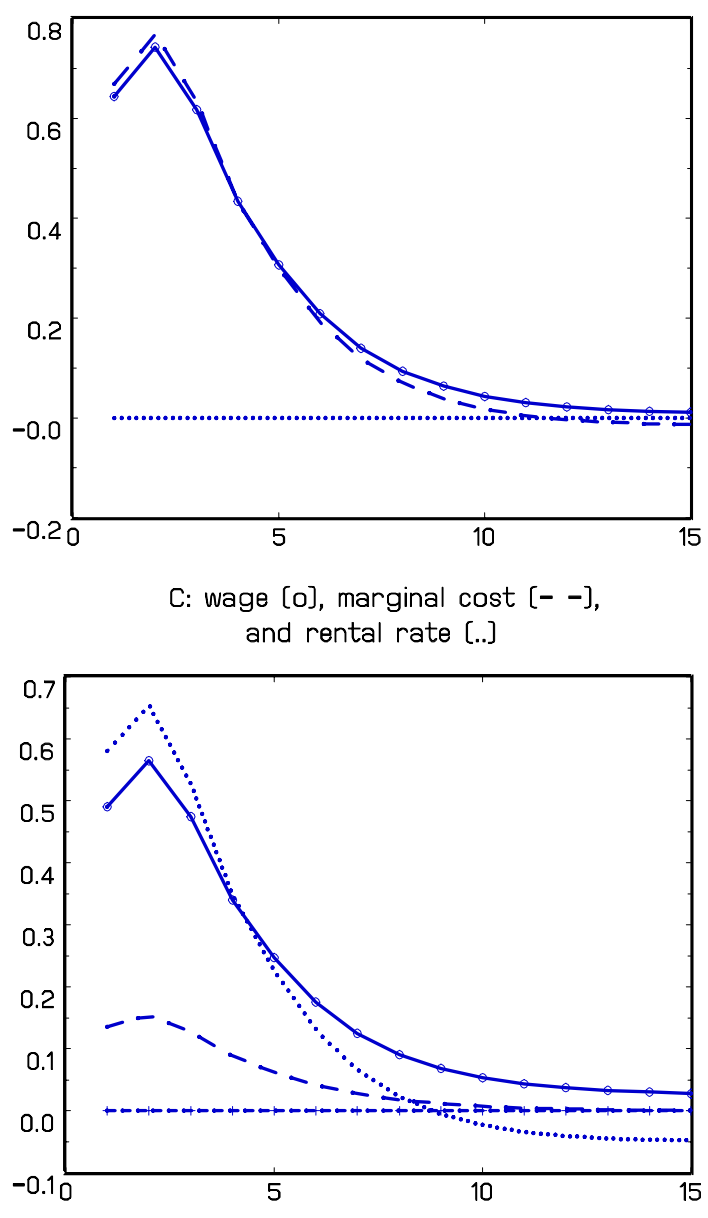

E: total consumption [o], investment [- - ], and basic consumption [. .]

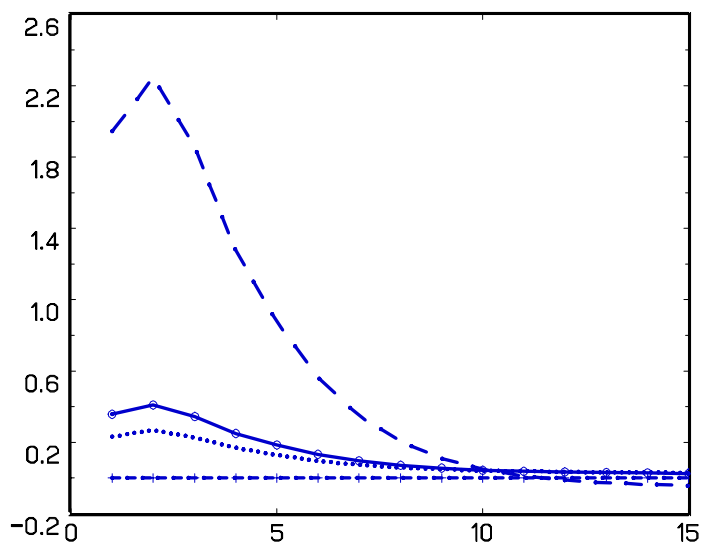

B: participation [o], hours per worker [- -], and utilization [. .]

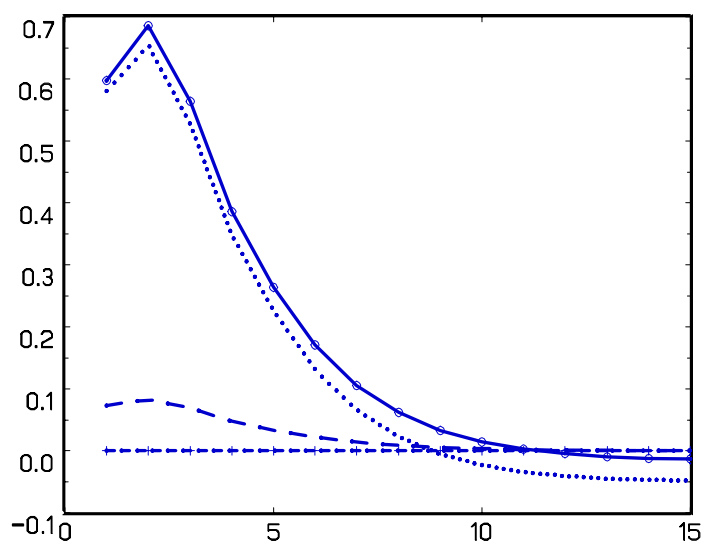

D: P* [o], price level [- -], and nominal money stock [. .]
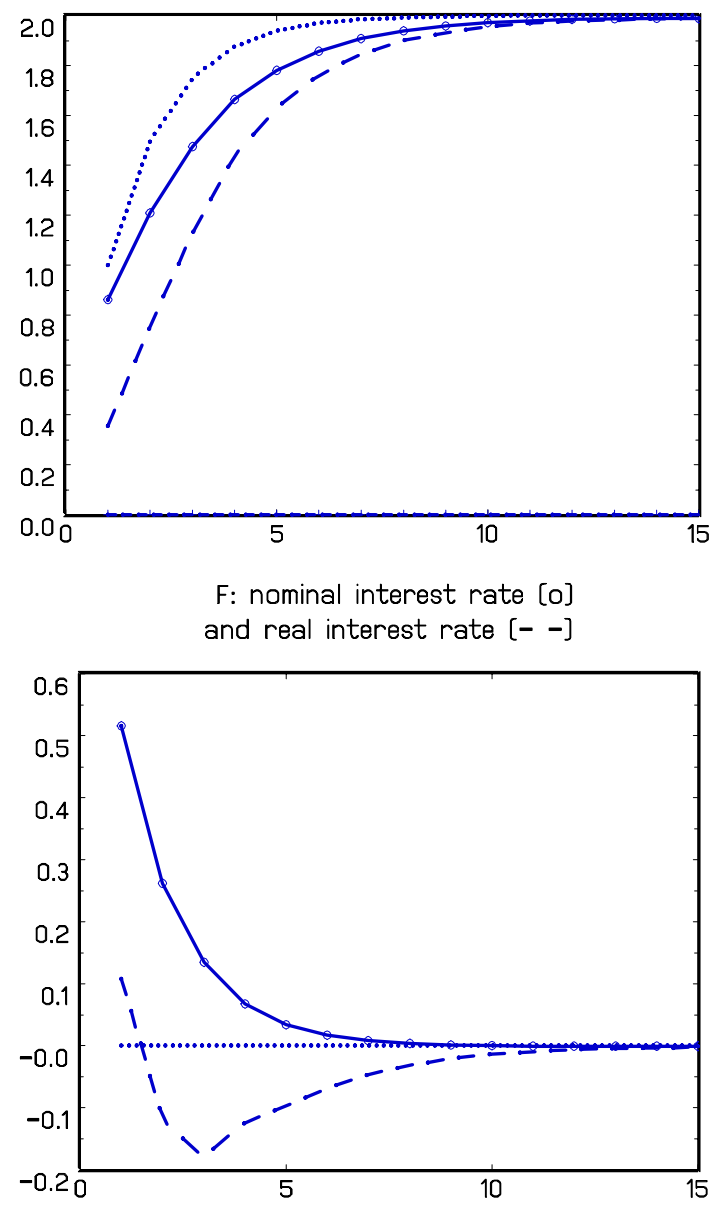


\section{Figure 5.3 Benchmark with SDP}

A: output [o], labor input [- - ], and materials [. .]
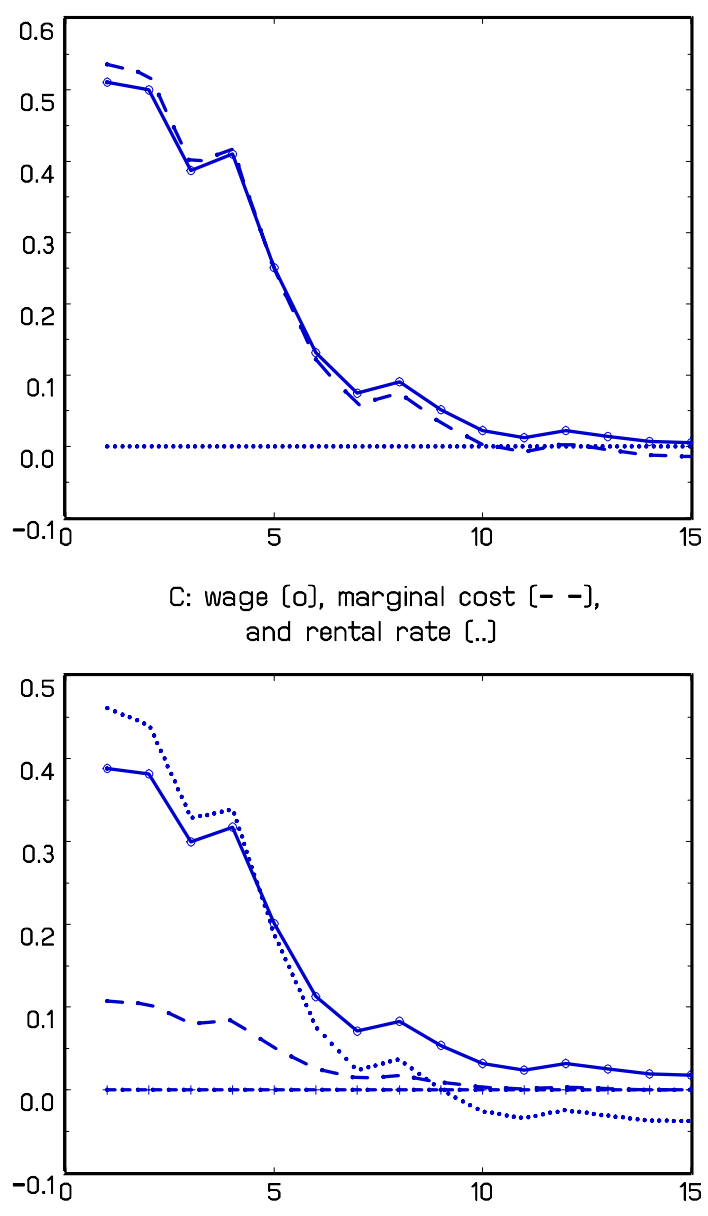

E: total consumption [o], investment [- -], and basic consumption [. .]

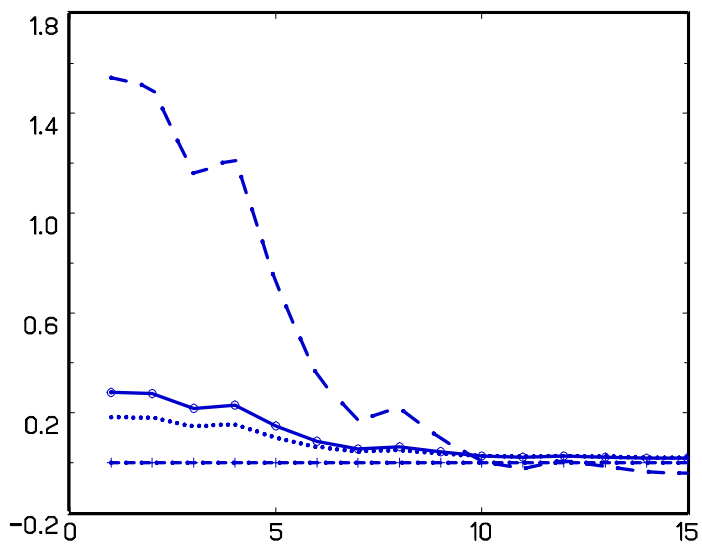

B: participation [o], hours per worker [- -], and utilization [. .]

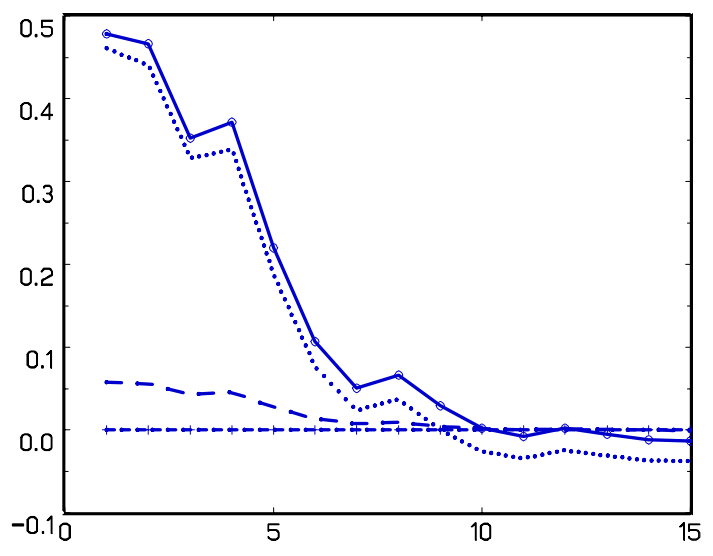

D: P* [o], price level [- -], and nominal money stock [. .]
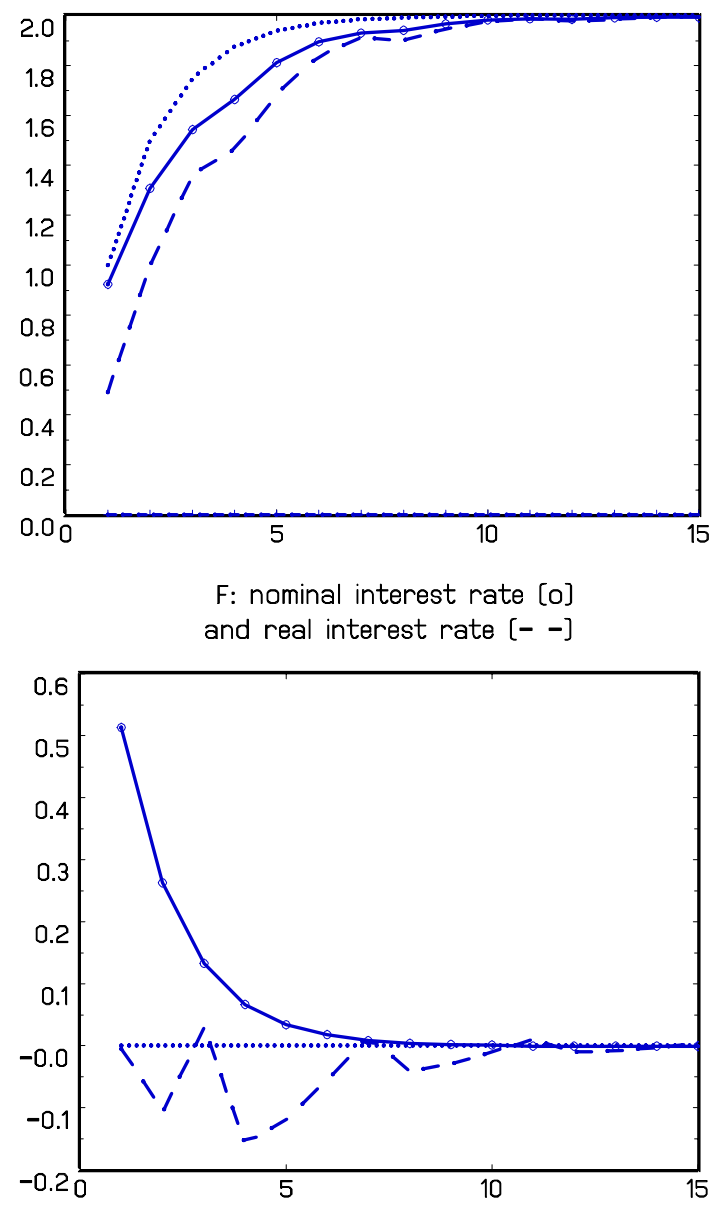


\section{Figure 5.4 Sensitivity of Responses in output [o] and marginal cost [- - ]}

A: Standard view

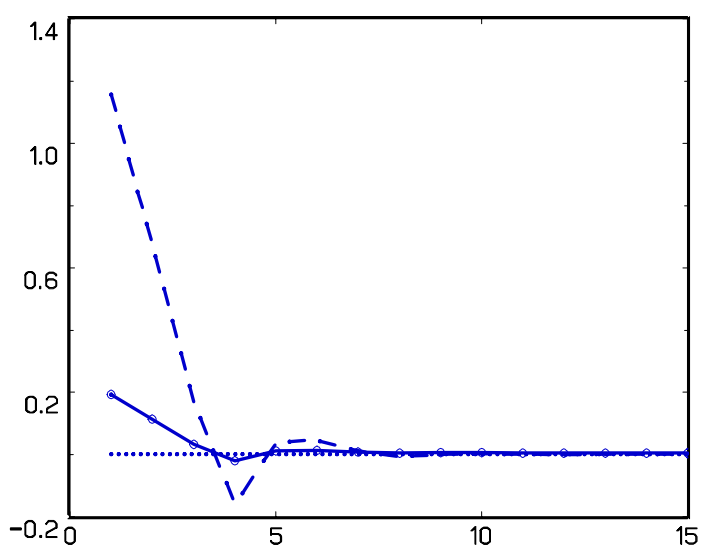

C: Materials but relatively inelastic factors

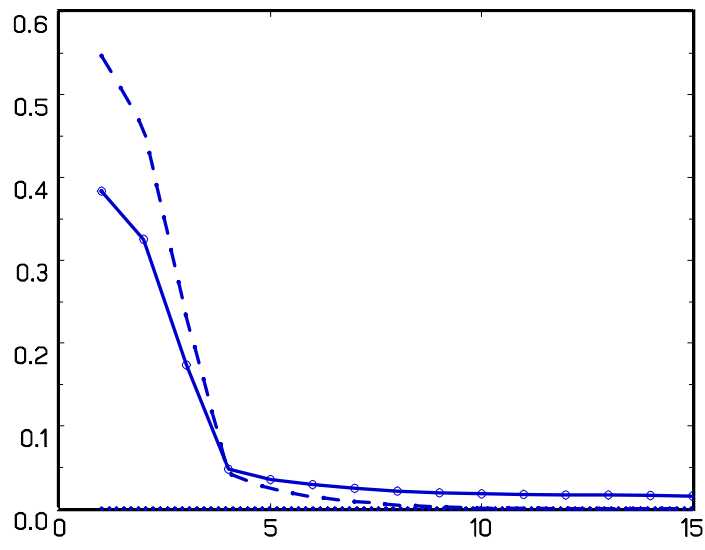

E: Materials and elastic utilization

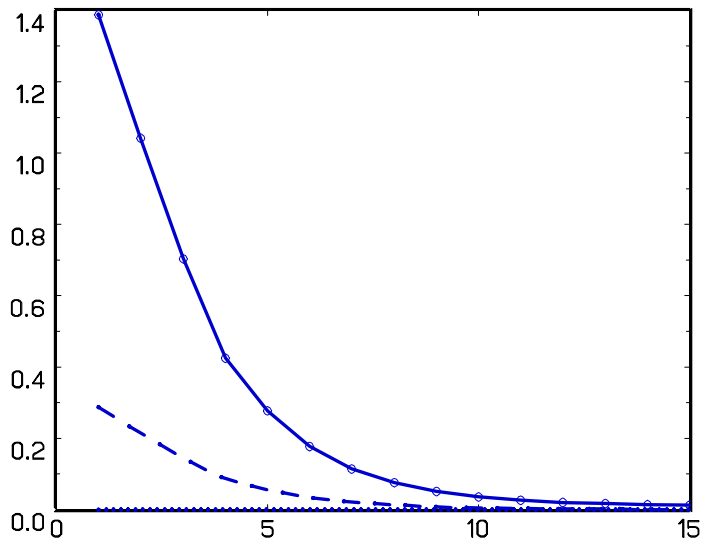

B: Elastic factors but no materials input

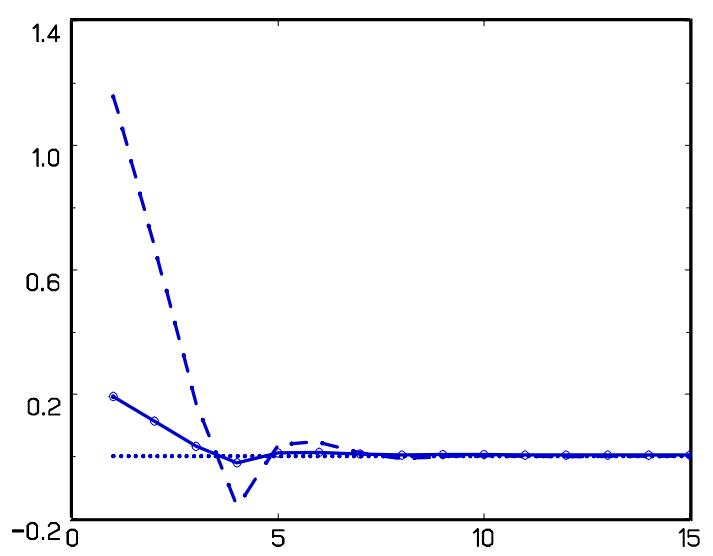

D: Materials and elastic labor

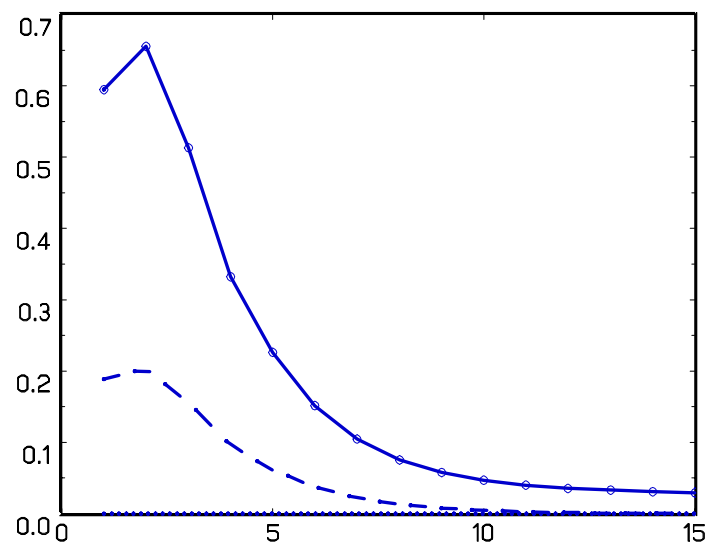

F: Bencmark

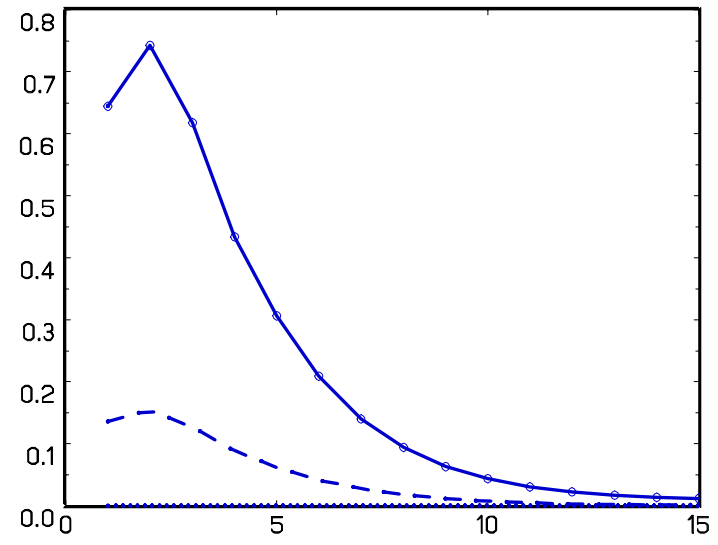




\section{Figure 5.5 Small money demand elasticity}

A: output [o], labor input [- - ], and materials [. .]
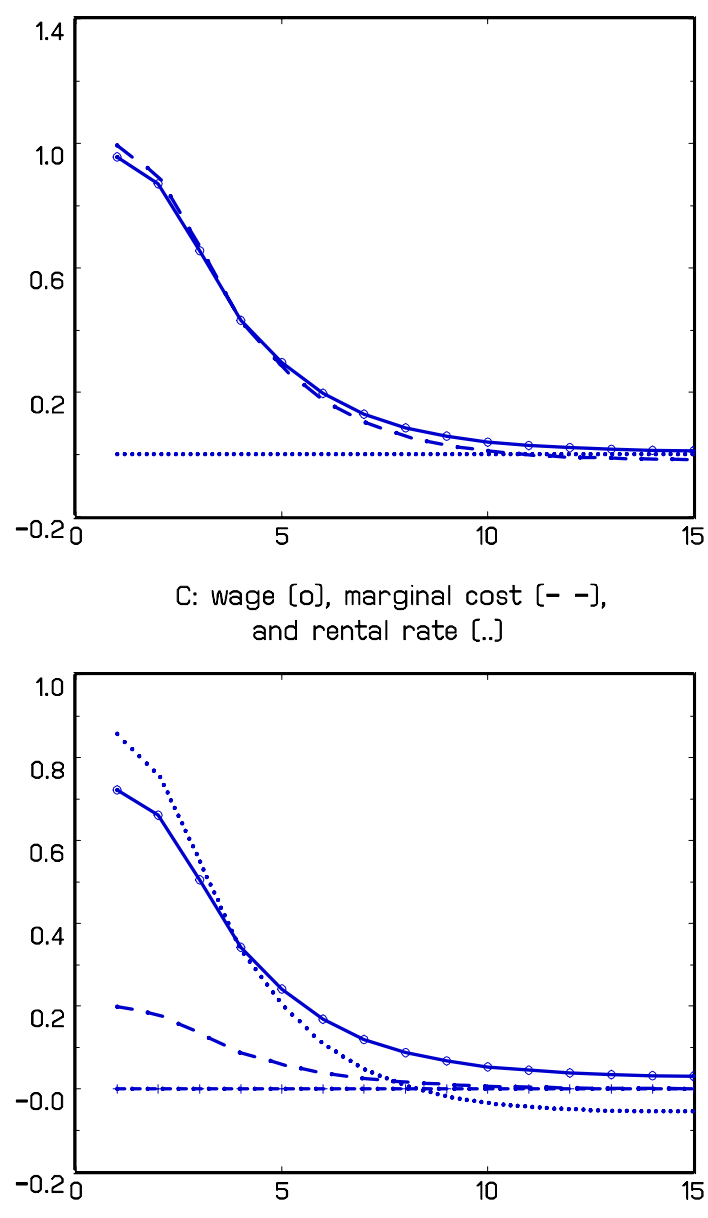

E: total consumption [o], investment [- - ], and basic consumption [. .]

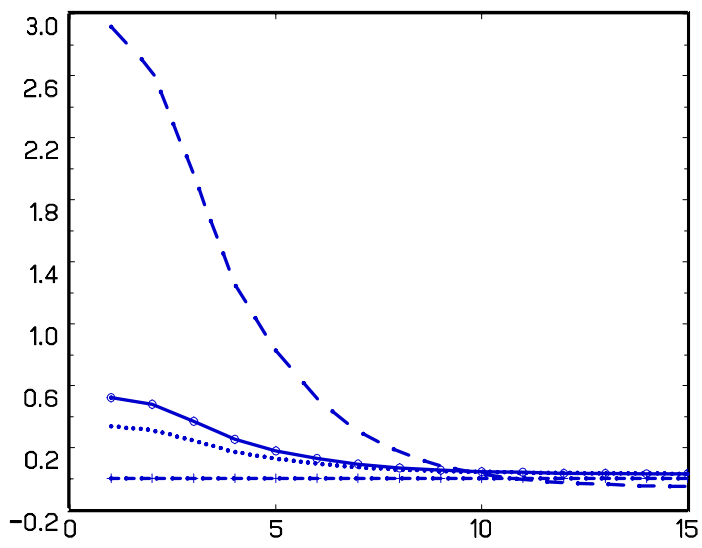

B: participation [o], hours per worker [- - ], and utilization [. .]

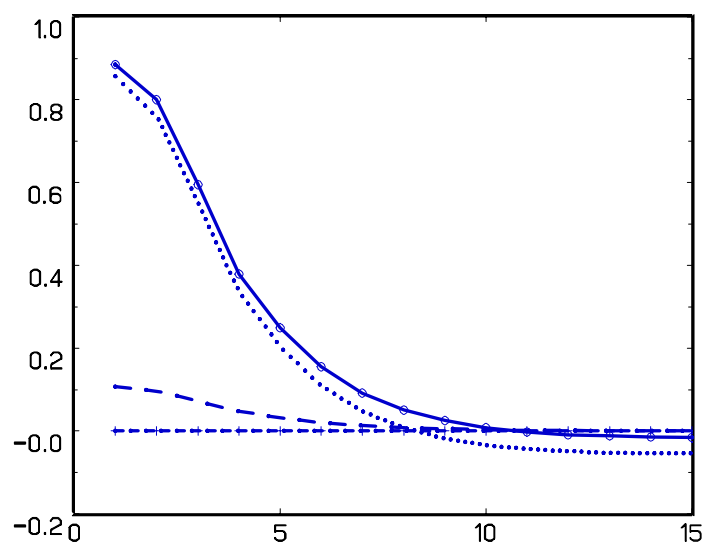

$\mathrm{D}: \mathrm{P} *[0]$, price level [- - ], and nominal money stock [. .]
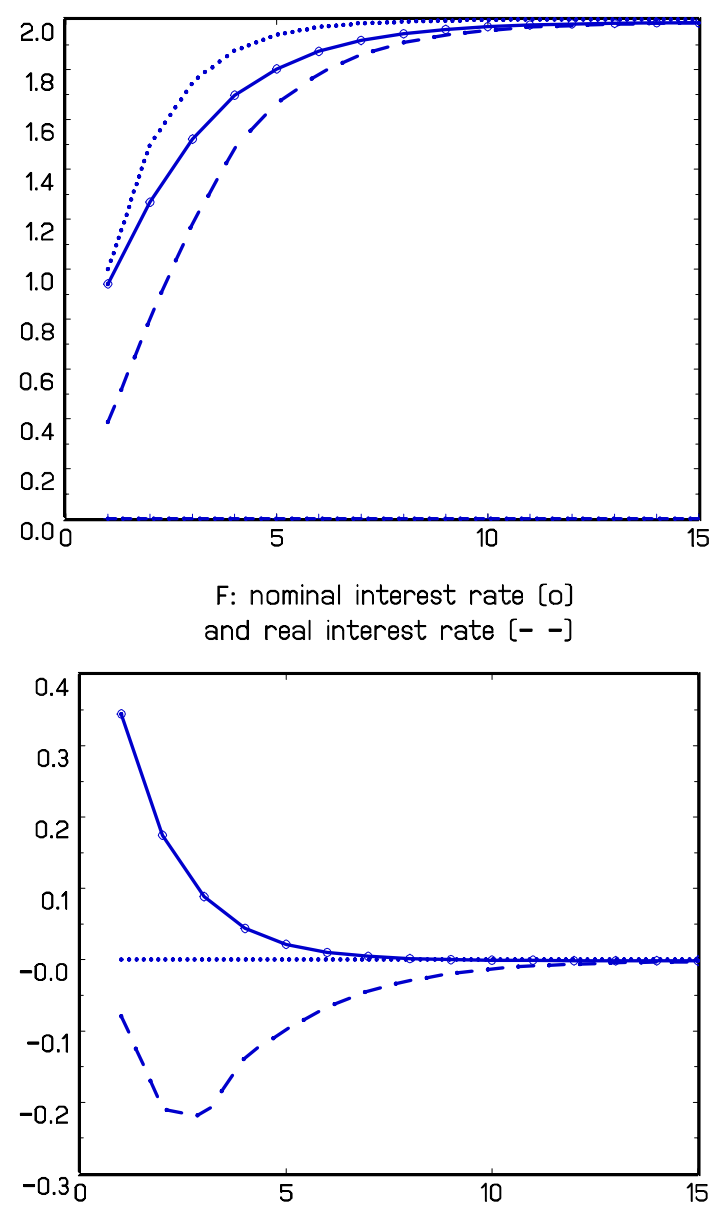


\section{Figure 5.6 Large money demand elasticity}

A: output [o], labor input [- - ], and materials [. .]
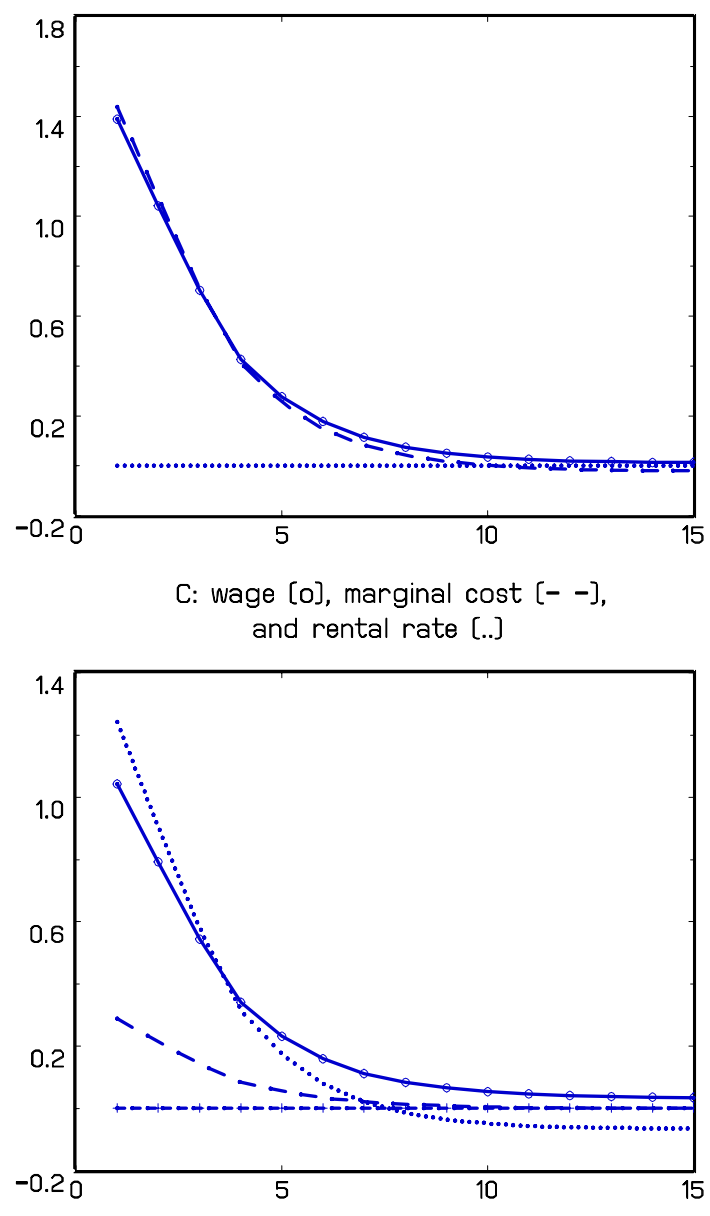

E: total consumption [o], investment [- - ], and basic consumption [. .]

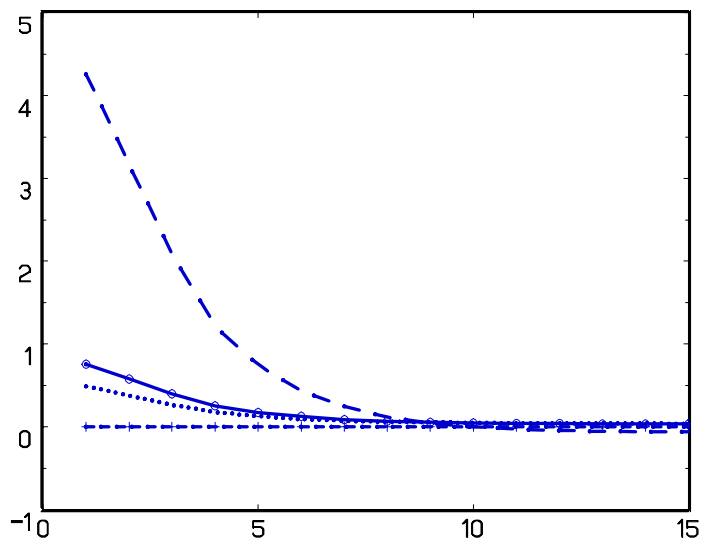

B: participation [o], hours per worker [- - ], and utilization [. .]

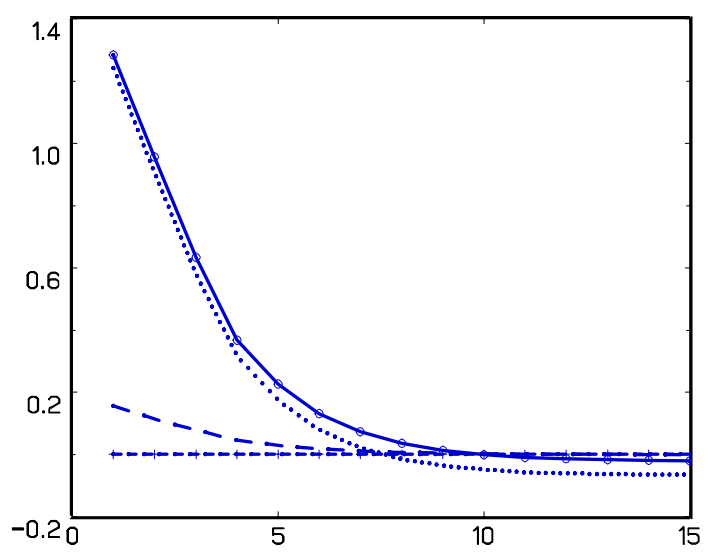

$\mathrm{D}: \mathrm{P} *[0]$, price level [- - ], and nominal money stock [. .]
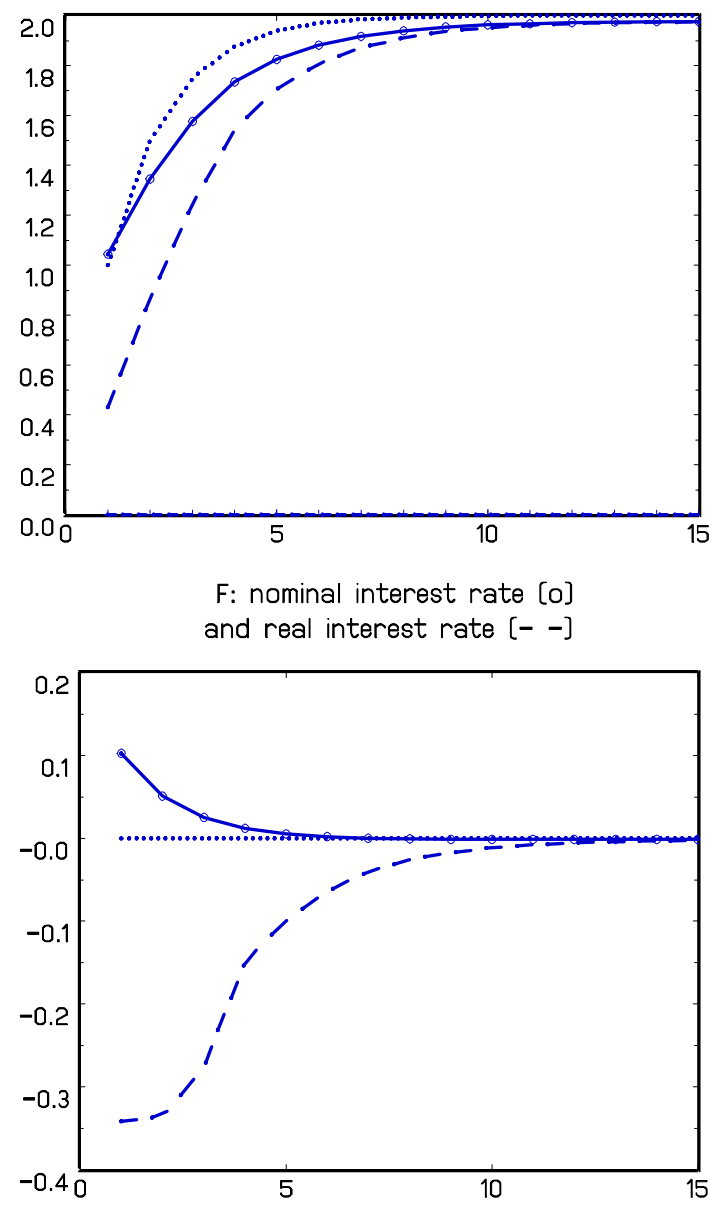